\title{
Quantifying Site-Specific Environmental Variance for Life-History Analyses: A Novel Application of Dendrochronology
}

\author{
by
}

Glenn D. Murray

\begin{abstract}
A thesis submitted to
The Faculty of Graduate Studies and Research In partial fulfilment of the requirements for the degree of Master of Science
\end{abstract}

\section{Department of Biology}

\author{
Carleton University \\ Ottawa, Ontario
}

(C) 2005, Glenn D. Murray 


$\begin{array}{ll}\begin{array}{l}\text { Library and } \\ \text { Archives Canada }\end{array} & \begin{array}{l}\text { Bibliothèque et } \\ \text { Archives Canada }\end{array} \\ \begin{array}{l}\text { Published Heritage } \\ \text { Branch }\end{array} & \begin{array}{l}\text { Direction du } \\ \text { Patrimoine de l'édition }\end{array} \\ \begin{array}{l}\text { 395 Wellington Street } \\ \text { Ottawa ON K1A ON4 }\end{array} & \begin{array}{l}\text { 395, rue Wellington } \\ \text { Ottawa ON K1A ON4 } \\ \text { Canada }\end{array}\end{array}$

Your file Votre référence

ISBN: 0-494-13469-0

Ourfile Notre référence

ISBN: 0-494-13469-0

NOTICE:

The author has granted a nonexclusive license allowing Library and Archives Canada to reproduce, publish, archive, preserve, conserve, communicate to the public by telecommunication or on the Internet, loan, distribute and sell theses worldwide, for commercial or noncommercial purposes, in microform, paper, electronic and/or any other formats.

The author retains copyright ownership and moral rights in this thesis. Neither the thesis nor substantial extracts from it may be printed or otherwise reproduced without the author's permission.
AVIS:

L'auteur a accordé une licence non exclusive permettant à la Bibliothèque et Archives Canada de reproduire, publier, archiver, sauvegarder, conserver, transmettre au public par télécommunication ou par l'Internet, prêter, distribuer et vendre des thèses partout dans le monde, à des fins commerciales ou autres, sur support microforme, papier, électronique et/ou autres formats.

L'auteur conserve la propriété du droit d'auteur et des droits moraux qui protège cette thèse. $\mathrm{Ni}$ la thèse ni des extraits substantiels de celle-ci ne doivent être imprimés ou autrement reproduits sans son autorisation.
In compliance with the Canadian

Privacy Act some supporting forms may have been removed from this thesis.

While these forms may be included in the document page count, their removal does not represent any loss of content from the thesis.
Conformément à la loi canadienne sur la protection de la vie privée, quelques formulaires secondaires ont été enlevés de cette thèse.

Bien que ces formulaires aient inclus dans la pagination, il n'y aura aucun contenu manquant.

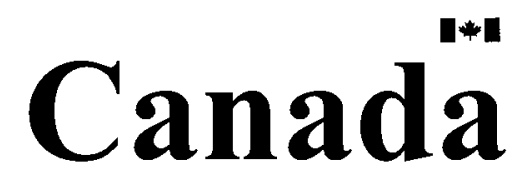




\begin{abstract}
Under temporal environmental variance, selection is expected to result in "bet-hedging" strategies - traits that maximize the geometric-mean fitness over generations. The degree to which an organism hedges its bets should be directly related to the degree of unpredictability characterizing its selective environment. Bet-hedging theory is difficult to test, however, both because traits must be studied over multiple generations and because no suitable measure of environmental variance exists. Here I review contemporary techniques of measuring environmental variables and of reconstructing climate histories. I then develop a novel method of quantifying historical environmental variance through use of dendrochronology, or tree ring analysis. The goal is to obtain a long-term, biocentric measure of site-specific environmental variance, which may then be used to study the fitness associated with observed life history characteristics. Results using archived data from two tree species from a total of 37 sites in Eastern North America show that it is possible to detect differences among sites in environmental unpredictability using these techniques, independent of site coordinates and site proximity. This tool has the potential to provide a framework for the study of selective environmental variance required to test hypotheses on the occurrence of bet-hedging traits in the field.
\end{abstract}




\section{Acknowledgements}

I'll start by thanking Dr. Andrew Simons for taking me on as his first M.Sc. student and sticking with me to the end. From the field to the lab, from Canada to Poland, I truly enjoyed my time working and learning with you and hope the feeling is mutual. I would also like to thank my committee members; Dr. Naomi Cappuccino and Dr. Gabriel Blouin-Demers; for their comments, criticisms and feedback which helped me produce this thesis. Thank you to Dr. Meltem Tuna for her statistical advice. While much of what we discussed did not make it into the final thesis, your time and efforts on my behalf were appreciated. I would like to thank National Resources Canada for granting me access to the Petawawa Research Forest for field sampling.

There are many people I should also thank for their role in making my time at Carleton so much more than can be measured through scholastic achievement. I've made so many great friends who have enriched my time here. Thanks to Dave Ladd, for making himself the butt of so many jokes and saving me the trouble. You've provided so many humorous moments, from "sinking the boat", to those deep philosophical discussions on portability and your generosity in enlightening everyone on the Canadian tax code. Thanks to Moshi Kotierk for being such a great friend over the years. Who could have known that your first "Moshi-thoughts", regarding the impact of the potato famine on my ancestors while searching for insects in the Fletcher Wildlife Gardens, would somehow lead to us establishing the long-lasting and ever popular "breakfast club", and a friendship to outlast it. To Erik Klingbeil who insisted on filling my head with more knowledge of jeeps than I'd ever hoped (or really wanted) to know. Further thanks to Julie Slow for providing an endless supply of faux-cheese snacks and other 
novelty food items. Marc Lajeunesse - "the genius" - the nickname that stuck in spite of Moshi's poor grasp of French, rather than because of it. I'd be remiss if I didn't extend my thanks to the others who helped make the grad office more than just a place for work, notably Carmen Gibbs, Donna Yee and Darryl Edwards. I would also like to thank Dan McPhee for all the distractions (and Kurt Cobain does indeed owe our generation in spades). Thanks to Andrea for all the intangibles, and helping keep me sane.

During the process of completing this thesis I have been privileged to interact with and learn from so many people that I would like to beg forgiveness from those whom I've had to leave out in an attempt to keep this short. Know that your contributions were valued none the less.

Finally, thank you to my parents for making this possible through their love and support over all these years. Dad, you swore you wouldn't believe it until you saw the proof in your hands, so perhaps this will do it. 


\section{Table of contents}

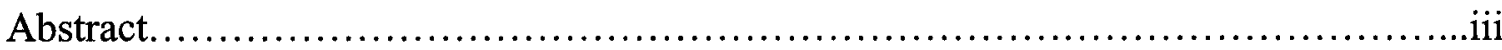

Acknowledgements...............................................................

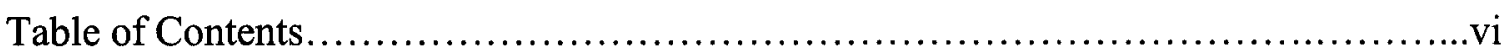

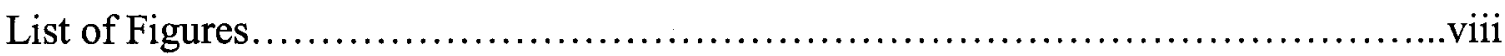

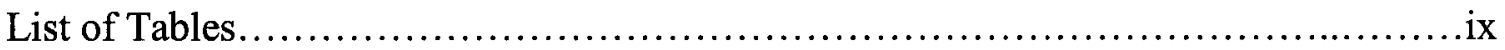

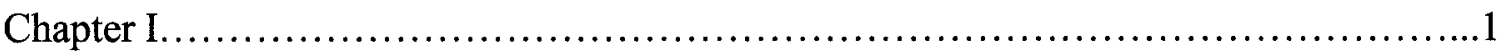

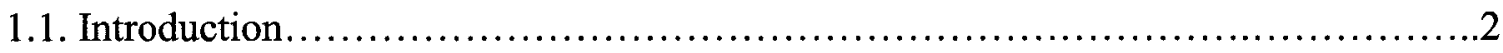

1.2. Environmental variation and fitness...............................................

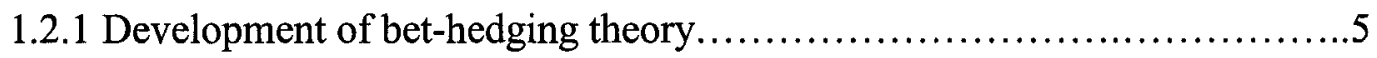

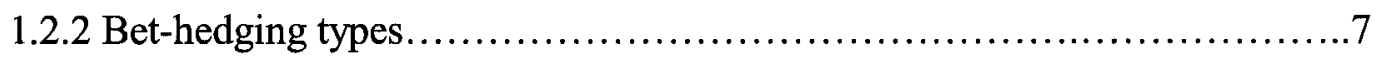

1.2.3 Difficulties inherent to testing bet-hedging..............................

1.3. Detecting variation to examine bet-hedging ......................................11

1.4. Methods of reconstruction of environmental variation..............................15

1.4.1 Historical records .................................................. 18

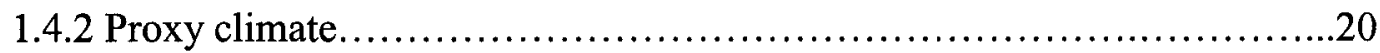

1.4.2.1 Population studies.........................................20

1.4.2.1a Temporal series for studying variation...................22

1.4.2.1b Spatial series for studying variation.....................23

1.4.2.2 Layered deposits........................................27

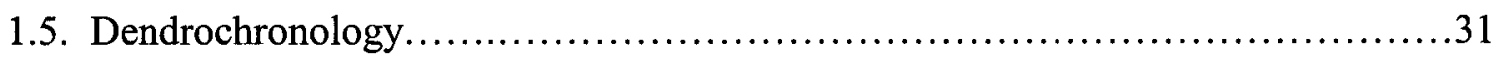

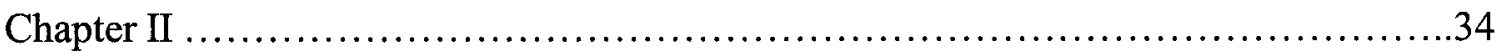

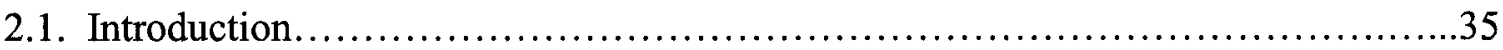




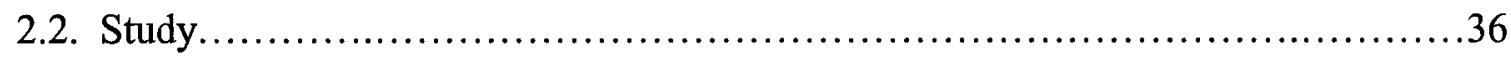

2.3. Methods............................................................... 37

2.3.1 Species and site selection..................................... 37

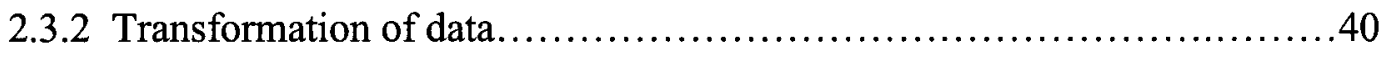

2.3.3 Data analysis...................................................41

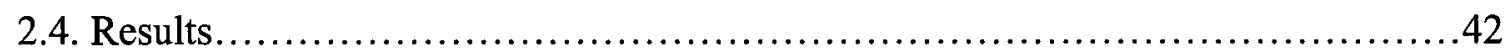

2.4.1 Detecting site-specific differences in environmental variation............42

2.4.2 Testing for trends in environmental variation.........................43

2.5. Discussion...........................................................

2.5.1 Detecting differences in site-specific environmental variation.............62

2.5.2 Detecting trends in environmental variation.........................62

2.5.3 Future considerations...........................................66

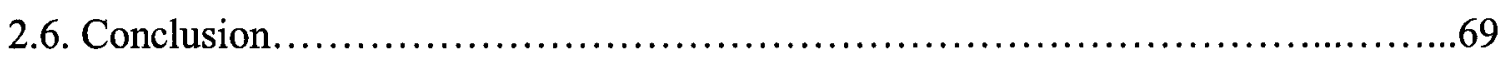

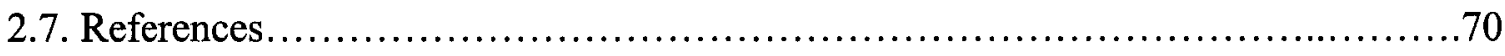




\section{List of Figures}

1. Effect of climate variables on tree-ring growth..............................16

2. Biotic filtering of abiotic environmental inputs.............................17

3. Window of reference for viewing environmental variation......................22

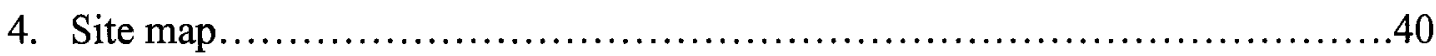

5. Representative site tree comparison for Tsuga canadensis......................52

6. Representative site tree comparison for Pinus strobus.........................53

7. Correcting for differences in mean ring-width in $T$. canadensis.................54

8. Correcting for differences in mean ring-width in P. strobus ....................55

9. Relationship between latitude and altitude in $T$. canadensis....................56

10. Effect of linear distance on differences in variation in T. canadensis.............60

11. Effect of linear distance on differences in variation in P. strobus...............61

12. Tree-ring growth used to detect quality of past growing seasons................68

13. Accumulation of variation at two different sites............................69 


\section{List of Tables}

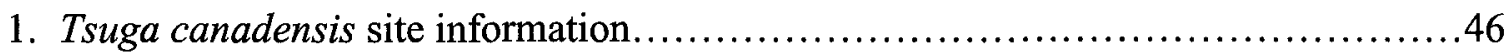

2. Pinus strobus site information................................................... 47

3. ANOVAs on coefficients of variation...........................................48

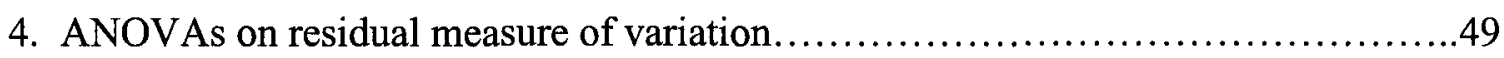

5. Tukey's HSD test on $T$. canadensis...........................................50

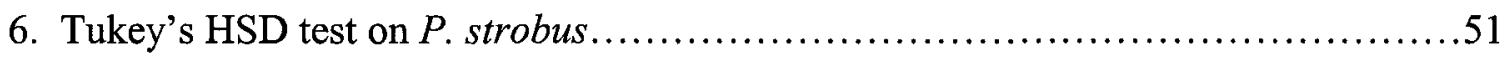

7. T. canadensis - multiple linear regression - Latitude, Longitude and Altitude..........57

8. P. strobus - multiple linear regression - Latitude, Longitude and Altitude.............58 


\section{Chapter I}

\section{An assessment of measures of environmental variation}




\subsection{Introduction}

Within-generation reproductive output has traditionally been used as a measure of fitness. More recently, however, evolutionary theorists have posited that minimizing the variance in reproductive success would result in greater long-term success when environments vary randomly, such as in real world scenarios (Gillespie, 1974; Seger and Brockmann, 1987; Philippi and Seger, 1989; Danforth, 1999, Simons, 2002). This newer approach to evolutionary theory is termed bet-hedging theory and predicts that individuals 'sacrifice' short-term fitness to maximize long-term fitness. Bet hedging is difficult to test, largely because environmental variance is difficult to quantify; therefore, theoretical work on this subject has relied on arbitrary levels of environmental variance selecting for "life-history" characters.

Unfortunately, because so-called bet-hedging traits appear to be suboptimal under short time scales or constant conditions, it is difficult to determine if they are truly examples of bet-hedging or merely maladaptive (Simons \& Johnston, 2003).

Evolutionary constraints may limit adaptation, resulting in characteristics that are truly maladaptive, yet are interpreted as bet-hedging traits simply because they do not serve to maximize short-term fitness and this suboptimality fits a qualitative prediction of bethedging (Simons \& Johnston, 2003).

Because the evolution of bet-hedging traits depends on the extent of environmental variance, what is needed to effectively test bet-hedging theory is a framework for quantifying the environmental variance under which the organism being studied has evolved. To provide such context, a record of environmental variation that occurs on a time scale relevant to the evolution of traits of the target organism is needed. While records of environmental variables (such as temperature and precipitation) are 
available, it is difficult to interpret how these multiple factors interact to influence the fitness of a living organism. This difficulty could be circumvented through use of a biocentric measure of environmental variation, incorporating the fluctuations of multiple climate variables into a single signal.

In this chapter, I will begin by discussing the importance of environmental variance in selecting for presently observed life history characteristics. The principal aim of this chapter is to provide a review of the various candidate techniques for determining a history of site-specific environmental variance. I will conclude the chapter by making a case for the use of the techniques of tree-ring analysis, or dendrochronology, as an ideal biocentric measure of environmental variance.

\subsection{Environmental variation and fitness}

Darwin's theory of natural selection (Darwin, 1859) was revolutionary because it described a simple yet powerful mechanism for how evolution occurred. Under traditional selection, fitness is assigned to individual phenotypes based on their relative genetic contribution to the next generation. These differing contributions can be the result of differential fecundity, differential survival, or both (Slatkin, 1974). How lifehistory strategies have evolved to maximize this contribution depends on the organism's selective environment. Life-history strategies in plants and animals involve a diverse range of parameters, including (but not limited to) brood size, offspring size, gamete dispersal methods, and timing of reproduction. Estimation of these parameters is complicated by the fact that they are not fixed, but exhibit plasticity in form (size of offspring) and timing of reproduction.

A traditional view is that organisms evolve continuously towards an ideal state, or fittest strategy for a given environment. The problem with a short-term approach to the 
study of life-history traits is that a strategy maximizing fitness for a given generation might not be representative of one which will maximize fitness over the long term. As an organism cannot be expected to know the exact conditions it will experience during a given season - except in a perfectly stable environment, which cannot be found in nature maximizing its fitness for a given set of environmental conditions could result in it being maladapted to subsequent conditions. In essence, the traditional "best strategy" may be constantly changing due to changing selective pressures imposed on an organism by both biotic and abiotic elements of its environment. Because natural selection acts continuously, seemingly advantageous short-term adaptations may continually be lost as the environment fluctuates (Simons, 2002). This continual short-term fluctuation in trait optima highlights the importance of understanding how the environment has changed in the past, and how organisms respond to those changes.

Environmental changes that are predictable (such as changing seasons) are expected to result in strategies that maximize reproduction. Not all variation is predictable, however, and even seasonality can vary unpredictably (wetter, dryer, colder, warmer, shorter, longer, etc.) and such changes may have a significant impact on the reproductive success of individuals. Response to selection is most rapid under strong and constant selection (Griffiths, et al., 1996). In cases where environments change unpredictably, theory suggests that strategies are selected for that will ensure reproductive success despite this unpredictability.

Commonly accepted evolutionary theory holds that natural selection favours traits that maximize the number of surviving offspring produced by an individual, assumed to be determined through maximizing an individual's expected contribution to the next generation. Exceptions to this rule have been noted, however, in certain cases where an 
individual's long-term fitness is increased through the evolution of traits that reduce the number of offspring produced in a given season. Such traits evolve if they serve to reduce the variance in fitness $(w)$ over multiple generations (Seger \& Brockman, 1987).

Such strategies evolve because they maximize the geometric mean fitness (GMF):

$$
\left(w_{1} * w_{2} * w_{3} * w_{4} * \ldots * w_{\mathrm{n}}\right)^{1 / \mathrm{n}}
$$

at the expense of the arithmetic mean fitness (AMF):

$$
\frac{w_{1}+w_{2}+w_{3}+w_{4}+\ldots+w_{\mathrm{n}}}{\mathrm{n}}
$$

(where $w_{\mathrm{i}}$ is the fitness in generation i).

In the case of a completely unvarying environment, the geometric mean fitness and arithmetic mean fitness are equal. The geometric mean is sensitive to variance, and in particular, if any term is zero, the geometric-mean fitness will also be zero. Because fitness over generations is multiplicative rather than additive, the geometric mean is a better measure of fitness than the arithmetic mean. The geometric mean is strongly influenced by low fitness values, and is thus maximized when fitness variance is low (Philippi \& Seger, 1989). Strategies which maximize long term fitness (geometric mean) at the expense of short term fitness have been termed bet-hedging (Slatkin, 1974).

\subsubsection{Development of bet-hedging theory}

Bet-hedging theory finds its origins in a paper by Dempster (1955) for his theoretical treatment of GMF. Cohen (1966) advanced the field by presenting a mathematical model demonstrating diversified bet-hedging in desert annuals in an attempt to explain observations on seed dormancy. Cohen's model makes several 
testable predictions. The first is that within a species, the fraction of seeds germinating in each year should be directly correlated to the expectation of a "good year". The second is that any seeds not germinating under good conditions in a given year should germinate under similarly good conditions in subsequent years. While Cohen's model does not specifically address the individual, bet-hedging theory has allowed this argument to be extended to make predictions about individuals.

Gillespie (1974) explains how a seemingly less-fit allele can rise to fixation within a population simply through conferring lower temporal variation in fitness. In this paper, Gillespie demonstrated that natural selection can act on within-generation variance in offspring number. Gillespie concluded that the advantage that a genotype gains though producing many offspring in a good year does not balance the disadvantage from producing few offspring in a bad year. Through decreasing the variance in offspring number, an individual increases long-term reproductive success.

In 1974, Slatkin published a brief commentary in Nature, titled "hedging one's evolutionary bets." In this letter, Slatkin highlighted the work of Gillespie and proposed a broader application for his ideas. Slatkin offered that contemporary models placed too great an emphasis on contribution to the next generation as a measure of fitness. He notes that population geneticists do not fully understand how natural selection acts on most of the genome, or even whether it affects much of it at all (Slatkin, 1974). Prior to Gillespie's 1974 paper, selection resulting from differential variance in offspring number had been ignored by theoreticians in spite of its obvious importance to the evolution of life-history strategies. Slatkin (1974) concludes that while many geneticists have assumed otherwise, the evolution of life-history strategies involves more than simply the maximization of reproductive potential. This letter represents the first time that the 
popular term "Bet-hedging" was applied to a reproductive strategy that maximizes geometric mean fitness.

Seger and Brockman (1987) and Philippi and Seger (1989) formalized the place of bet-hedging theory as a tool for investigating the fitness of reproductive strategies. Seger and Brockman (1987) presented bet-hedging theory as it is currently accepted, using seed and egg diapause to illustrate the theory. They listed the testable characteristics currently associated with a bet-hedging system:

1. Offspring from the same genotype should mature in different seasons under the same conditions.

2. The maturing portion should be proportional to the probability of a good season. Philippi and Seger (1989) defined two different categories of bet-hedging strategy conservative and diversified - and then provided examples of bet-hedging strategies, including seed germination and dormancy, insect diapause and offspring size and number.

\subsubsection{Bet-hedging types}

Conservative bet-hedging strategy is based on the principle that "a bird in the hand is worth two in the bush" (Seger \& Brockman, 1987). This conservative strategy involves a reduction in the variation in fitness over generations, at a potential cost to mean fitness. This can be explained by comparing two organisms that exist in a randomly fluctuating environment that has good seasons and bad seasons in equal abundance. If one organism is a good-season specialist it may have eight successful offspring in a good year and only two in bad years. The conservative bet-hedger has six in good years and three in bad years. While the specialist produces more offspring in good years (and has a higher AMF: $(8+2) / 2$, vs. $(6+3) / 2)$, the GMF of the bet-hedger is 
greater $\left((6 \times 3)^{1 / 2}\right.$ vs. $\left.(8 \times 2)^{1 / 2}\right)$ (increasing long term reproductive success) and this strategy will eventually become fixed within the population.

The second form of bet hedging (known as diversified bet-hedging) is associated with the expression "don't put all your eggs in one basket." This strategy involves the production of varied phenotypes that are less adapted to a stable (or even average) environment, but some of which will survive through even extreme conditions (Philippi \& Seger, 1989). The result of this strategy is the same as that of conservative bethedgers, in that it maximizes GMF through reducing the variance of mean for withingeneration fitness. This strategy, however, reduces the variance in long-term fitness for the genotype over generations through increasing the variance of fitness among individuals within generations (Philippi \& Seger, 1989).

Consider the same randomly fluctuating environment as in the conservative example. In this instance, there exists both a good-season specialist and a bad-season specialist. It might be more appropriate to think of hot and cold or wet and dry specialists. The diversified bet-hedger genotype produces phenotypes that are a mixture of both specialists. It turns out that, since its offspring average the mean fitness of the two specialists, the bet-hedger has higher geometric mean fitness than either specialist alone.

\subsubsection{Difficulties inherent to testing bet-hedging}

Conservative bet-hedging is difficult to detect as it entails producing fewer than expected offspring over the short-term. The difficulty in testing this strategy is in determining a non-risk spreading strategy as a null model for comparison. The problem associated with developing this alternate model is that it is virtually impossible to take into account all the factors that lead an organism to adopt a given strategy. Hopper (1999) indicates the danger of proposing hypothetical species that are perfect for the 
observed season, but are unrealistic in terms of the history of the organism and the pressures that may have guided its evolution. The genetic history of the organism may limit the ways in which it can evolve to adapt to an environment. Seemingly maladaptive strategies may simply be maladaptive, rather than bet-hedging strategies that have evolved to cope with varying environments. Alternatively, even strong evidence of trait suboptimality over extended periods of time does not preclude the possibility that the trait is a form of conservative bet-hedging, acting on a level of variance whose associated time scale is simply not being observed (i.e., long-term large fluctuations compared to which seasonal variations are of a minor nature; Simons, 2002; Simons and Johnston, 2003). This difficulty in forming a null model for comparison poses great challenges to anyone attempting to attribute life history traits to a bet-hedging strategy.

Diversified bet-hedging would seem to be more easily tested and has often been used to explain circumstances where phenotypic variation is found to be greater than expected. To detect this, however, a measure of the background of environmental variation must be available, as well as a measure of the fitness of phenotypic variants within these variable environments. Rather than testing the optimality of bet-hedging characters, the criterion for determining the presence of a bet-hedging strategy has simply been that the observed strategy seems to be maladaptive and so must be an example of bet-hedging (Hopper, 1999).

Knowledge of adaptive response to unpredictable variation is limited and has only relatively recently begun to gain the attention of researchers. The application of bethedging theory seems to hold great promise for explaining the evolution of traits in organisms faced with randomly fluctuating environments. Though a great deal of theoretical work has been conducted largely on seed dormancy (Cohen, 1966 and 1967; 
Gillespie, 1974; Slatkin, 1974; Venable and Lawlor, 1980; Bulmer, 1980; Cohen and Levine, 1985; Ellner, 1985, 1986, 1987; Brown and Venable, 1986; Philippi and Seger, 1989; Venable, 1989) and also on bud dormancy (Nilsson et al., 1996) and insect diapause (Menu, et al., 2000) few empirical studies have been conducted in which the evolution of bet-hedging strategies has been tested (Hopper, 1999).

There exist few empirical studies of bet-hedging (Philipi, 1993a and 1993b; Clauss and Venable, 2000 - seed dormancy; Simovich and Hathaway, 1997 - insect diapause). There are no studies with "unequivocal results" attributing the evolution of life history strategies to bet-hedging (Hopper, 1999).

While it is possible to make testable predictions of bet-hedging strategies involving phenotypic variation in different populations based on environmental uncertainty (Hopper, 1999), these types of studies are labour intensive as they involve tracking both fluctuating selection and its result over multiple generations. In fact, measuring trait optimality for a bet-hedging strategy over 10 generations involves an order of magnitude greater effort than a simple test of mean fitness (Simons and Johnston, 2003). A potential alternative to this approach would be to quantify the historical variance of sites, and then examine how the species within them have evolved to cope with that variation. Quantifying past environmental unpredictability would allow experimenters to examine strategies of individuals within that environment with knowledge of how selection pressures had acted on them in the past and determine whether or not their life histories do indeed conform to bet-hedging strategies.

To make predictions about trait evolution under environmental unpredictability, it is necessary to re-construct the history of environmental variation under which organisms 
have been evolving in order to make predictions about how they should have evolved to minimize the variance in their reproductive success.

\subsection{Detecting variation to examine bet-hedging}

The empirical testing of bet hedging theory has been hampered by the lack of quantitative data on historical levels of environmental variation. Theoretical models are often based on simplified "good year/ bad year" scenarios. Without quantitative data on levels of environmental unpredictability it is not possible to detect whether or not life history traits are indeed bet-hedging traits, or simply maladaptive. Some theoretical models have incorporated measures of environmental variation (Nilsson et al., 1996); theoretical levels of variable herbivory on plants containing dormant buds (Clauss \& Venable, 2000); precipitation records (Simons \& Johnston, 2003); variation in season length as determined by degree day accumulation, though this practice is rare. Quantitative tests of life history optimality are rare due to the labour involved in collecting data. Such questions are more often addressed with models used to generate qualitative predictions (Ellner, 1985). Predictions are often formed in the absence of real world limitations (in the case of dormant seeds: using estimations of dormancy survivorship to determine theoretical ideal germination fractions, while not including such difficult to model factors as density effects). These predictions are then 'tested', and conclusions drawn based on how results qualitatively correspond with the predicted outputs (Ellner, 1985).

Clauss and Venable (2000) performed one of the few rigorous empirical investigations of adaptive bet-hedging in desert annuals with precipitation data as a proxy for levels of environmental variance. They were able to detect a link between increasing germination fractions with decreasing environmental variance for populations measured 
in situ. However, field observations showed an opposite trend, and the seed fractions showed phenotypic plasticity in response to water availability and date within season. Physiological limitations to adjusting germination response to water availability may be reason for germination fractions not attaining a bet-hedging optimum each year (Clauss and Venable, 2000).

While precipitation data may be an acceptable model for environmental variance in desert environments, this measure would be an oversimplification in environments where a single resource is not so predominantly limiting to growth. Even in a desert environment, obtaining an accurate and relevant measure of precipitation is not limited to calculating how much water has fallen at a given site. Additional factors such as soil quality, wind, and cloud cover, to mention a few, all play a role in determining how much of that accumulated precipitation remains available to the biota after a precipitation event. In addition to the effects the environment has on available precipitation, obtaining longterm measures of precipitation is only possible from pre-existing weather stations, which are not always available in close proximity to a study site. To circumvent the limitations of such single-variable measurements, a method is needed that would provide biologists with a cumulative measure of the environmental unpredictability within a given site (as it applies to the model organism), so as to allow researchers to examine evolved life-history characters.

In the remainder of this chapter, I develop an argument for the use of dendrochronology - or tree-ring analysis - for the reconstruction of histories of environmental variance against which evolution of bet-hedging traits can be compared. While many other methods are available that have been used to reconstruct climates (and therefore have the potential for use in reconstructing environmental variance), not all 
provide suitable data with which to test the evolution of bet-hedging. In the following sections, I will present various techniques that have been used to reconstruct climate histories and that have the potential to provide measures of environmental unpredictability. I will address their strengths and weaknesses in terms of their application to the study of bet-hedging strategies and then conclude with an argument for dendrochronology as an ideal tool to address the dearth of localized data on levels of environmental variance.

Variation in the natural environment has been measured using both abiotic and biotic indicators. The rapid development of technology over the last few decades has led to an increase in the number of tools available for measuring climate variables. Recent history has seen the development of complex instruments allowing the user to track minute changes in temperature, humidity, atmosphere composition, etc.

While modern instruments allow scientists to detect far more than previously possible, the majority of instrument climate data available is based on fairly basic equipment and the data consist primarily of temperature and precipitation readings. The record provided through these instruments is short in evolutionary terms, rarely extending more than 150 years into the past (Stocker, 1999) with more complex data only available on shorter timescales. Reliable instrument data records are limited or absent for the period preceding 1850 , with large regions of central Asia being most notable for the paucity of the climate record (Thompson, 2000). While a 150-year time span of recordings would seemingly be acceptable for the study of short generation-time organisms, the records are extremely restrictive in that they tend to be limited to major population centres (Le Roy Ladurie, 1971) and so are poorly suited for comparisons of in-site variation, as sites of interest are often situated in remote locations. Also, because 
these records are often limited to temperature recordings, they do not provide adequate information to model a biotic response when so many other abiotic factors play a major role in determining that response.

The problems inherent in existing weather data continue to the present day: modern precision instrument readings of climate variables are restricted to sites in which the equipment is actually located. Because even small distances between instrument sites and the actual site of study can result in significant changes in the weather values being measured, their value to evolutionary study may be limited. Topographic effects, for example, can change the amount of rainfall at a site, as well as affecting prevailing winds, which will in turn affect available moisture levels through evaporation. It is also possible that rain falling on a study site might not fall at a nearby weather station. The use of weather stations for evolutionary studies on the impact of environmental variation is restricted by the fact that stations are dispersed across the landscape and are not always present near sites of interest for scientists studying natural populations. While researchers may elect to measure a wide scope of weather variables in the sites where their organisms of interest are located, these measures will accrue from the start of the study, and will not provide the required long-term record of local variation with which to address evolutionary questions.

A final problem associated with the use of instruments to track environmental variation is the difficulty associated with interpreting the effect of the many measured abiotic values on organisms. The complex relationship between recorded values and how they affect fitness is difficult to model. To use plants as an example, increased sunlight and temperature increase photosynthesis. However, without adequate available water, stomata close to retain moisture, limiting the uptake of $\mathrm{CO}_{2}$ and slowing photosynthesis. 
Seasons with increased rainfall serve to raise the levels of available water; however, the cloud cover associated with it leads to reduced sunlight and temperature and slowed photosynthesis. These basic relationships do not take into account the innumerable other factors that affect the complex interactions of climate and substrate that combine to result in plant growth, such as the formation of an annual tree ring (Fig. 1).

The response to a stochastic environment can be further complicated by thresholds of response within the organism itself (Laakso et al., 2001). Measures of abiotic variance do not necessarily translate linearly to a measure of biotic response. In effect, organisms "filter" the climate signal, often resulting in responses seemingly out of sync with observed climate fluctuations (Laakso et al., 2001). The filtered response can vary greatly, resulting in close or, alternately, inverse correlations between the individual and the climate signal being measured (Laakso et al., 2001). Laakso et al. (2001) present 3 examples of filters (asymptotic, symmetric and sigmoidal) that might depict how variation in an environment might be translated to variation in biological response (Fig. 2). The way in which environmental signals are affected by these filters will be reflected through variance in population size, even to the extent of extinction (Laakso et al., 2003).

A biotic measure of climate variation (incorporating the effects of 'biological filters') would serve to reduce the effect of the disconnect between environmental stochasticity and its effect on the biotic components of an ecosystem.

\subsection{Methods of reconstruction of environmental variation}

The limitations of the instrument record in providing data on the selective pressures driving evolution requires that alternative methods be considered. Methods of climate reconstruction must be investigated in the hopes of obtaining more complete data 


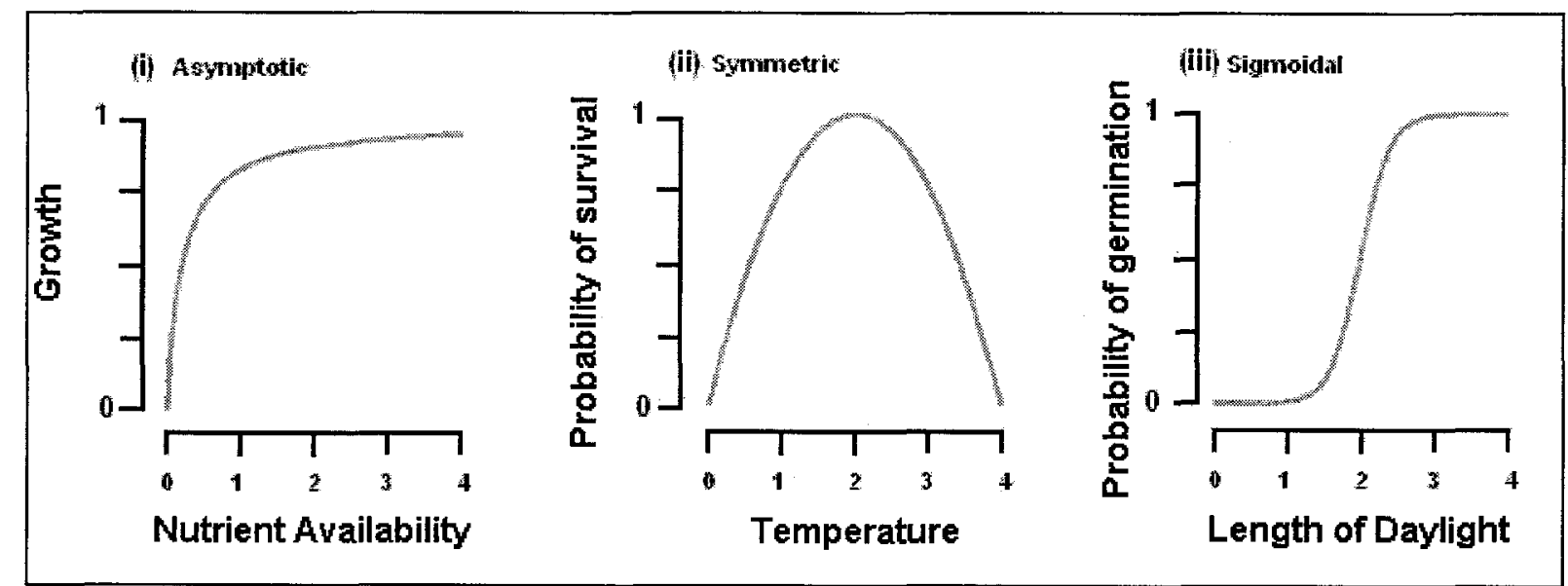

Fig 2. Three examples of how environmental signals might be interpreted by organisms, thereby producing a resulting in a non-linear relationship. (i) - increasing nutrient availability showing a smaller effect at higher availability due to saturation of the organism's uptake mechanisms. (ii) - A symmetric relationship demonstrating a "comfort zone" of temperature. As temperature moves away from that level (in either direction) the organism is less likely to survive. (iii) - A sigmoidal relationship between the environmental signal and organism response - represented here by the length of day being used as a germination cue by a seed. (Response types proposed by Laakso et al. , 2001) 


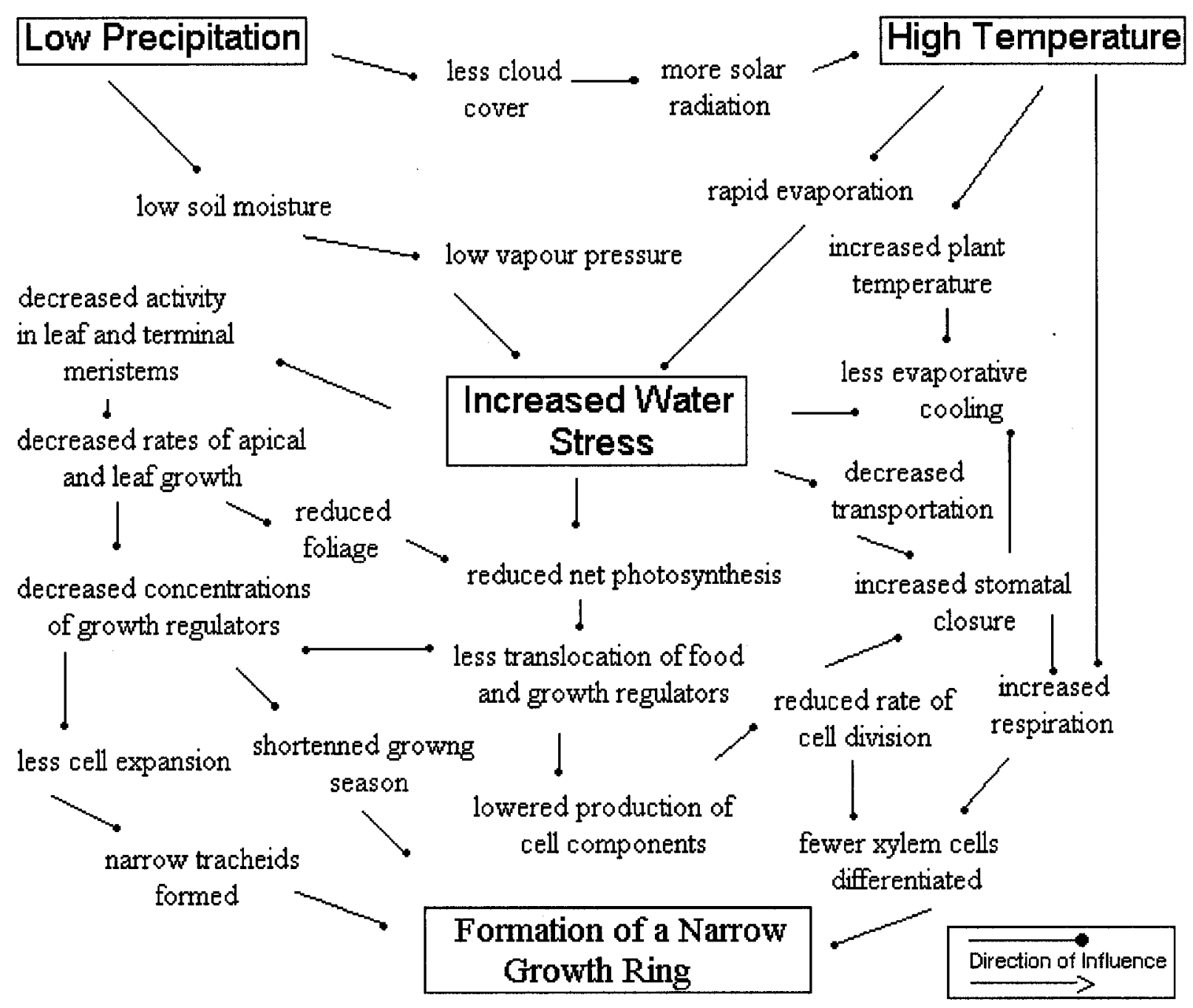

Fig 1. Model showing the complex interaction of two given states of variable climate parameters (temperature and precipitation) on the annual growth of a tree 
on the variability of past environments. The field of paleoclimate

reconstruction has developed to address the short duration of the instrument record through interpreting historical records such as crop yields (4.1), or through interpreting past climate based on its effect as recorded in biotic and abiotic elements of the ecosystems in which they are occurring, including extremely rare yet catastrophic events such as bolide impacts, evidenced by impact craters, and mass extinction events detectable through fossil records (Raup, 1991).

Spatial time series analyses, using either population or fossil based studies, have been used to detect and track climate change (Shaffer, et al., 1998). Spatial surveys from different time periods have been compared to interpret climate signals as evidenced by population change, such as changes in natural population sizes, as well as species assemblages, inferring a change in their environment that is potentially climate based (Gribbin, 1978; Goudie, 1992).

An alternative to these forms of analysis involves high resolution studies of environmental systems that result in a continuous deposition of material; examples of which include the annual growth rings of trees and corals, sedimentary deposits in lakes or oceans, as well as snow deposits at high altitudes or in the Polar Regions. Such analyses provide insight into environmental conditions which existed at the time the layered sediments were deposited.

\subsubsection{Historical Records}

It is possible to gain some insight into past climates through interpreting primary sources such as historical documents, which directly or indirectly reference weather conditions. Historical data available for this type of study include records for crop yields 
(grain, grapes, etc.), weather diaries, records of floods and droughts, taxation revenue based on agricultural economies, frost dates, glacier-extent and sea-ice conditions (Pittock, et al., 1978). Weather events or annual trends are often referenced in popular histories and some periods of time have been catalogued in detail through personal journals that gained circulation through publication (common examples include soldier's journals of military campaigns; Le Roy Ladurie, 1971). There exists a wide range of historical documentation of climate-related phenomena and paleoclimatologists have attempted to interpret this data and thereby reconstruct past climates (ex: Bryson and Julian, 1962; Le Roy Ladurie, 1971).

Problems associated with this form of reconstruction are numerous and varied. Any recorded accounts are greatly swayed by the experience of the recorder. A recorded deviation from "normal" weather in a given year is dependent upon what the individual recording the event's experience of "normal" is. The description of a season being cold or warm is relative to what the previous years have been. The memory of recent events can affect the way in which an observer records events (Fig. 3). A prolonged period of unusually cool winter temperatures could result in a return to mean temperatures being interpreted as unusually warm. Hence, this form of analysis is strongly subjective, and this must be accounted for when attempting to reconstruct climate history through such methods.

With constantly developing technology, agricultural yields can increase over short periods of time without an associated change in climate. The combined affects of artificial selection (i.e., husbandry) on crops, changing land usage and development of new techniques and tools all serve to distort the climate signal contained within these data records. Similarly, improvements in equipment and techniques can result in drastic 
changes in fish stocks, even to the point of driving certain species to extinction (LeRoy Ladurie, 1971). As an example, recent concerns over dropping lumber production in the United States were determined to be the result of changes in measuring techniques resulting in production values lower than would be shown using traditional measures (Zeide, 1992); a clear demonstration of the dangers of relying on production records to reconstruct climate.

\subsubsection{Proxy climate}

Instead of interpreting historical records, a perspective on climate variation can be obtained through the study of natural phenomena that are climate-dependant. Climate exerts a powerful influence on the function of the biosphere, and so opportunities exist in employing biological proxies in the reconstruction of climatic history. While initially coarse, continued refinement of these methods has allowed for detailed reconstruction of past climates (Goudie, 1992).

\subsubsection{Population Studies}

Animal and plant species have their own characteristic requirements to live and reproduce. A given location must have a balance between food supply and climate conditions for a given species to survive and prosper (Goudie, 1992; Sinka and Atkinson, 1999). Animal and plant populations are greatly affected by climate change, resulting in changes in population sizes and in ecosystem assemblies (Goudie, 1992; Sinka and Atkinson, 1999). Detecting these changes can allow for the reconstruction of the climate that resulted in the observed change (beneficial or detrimental) on species inhabiting a given environment. 
Such organism based studies are divided into two categories; those dealing with measurements of a given population or group of populations over time, and those dealing with changing assemblages of species in a given area over time. 


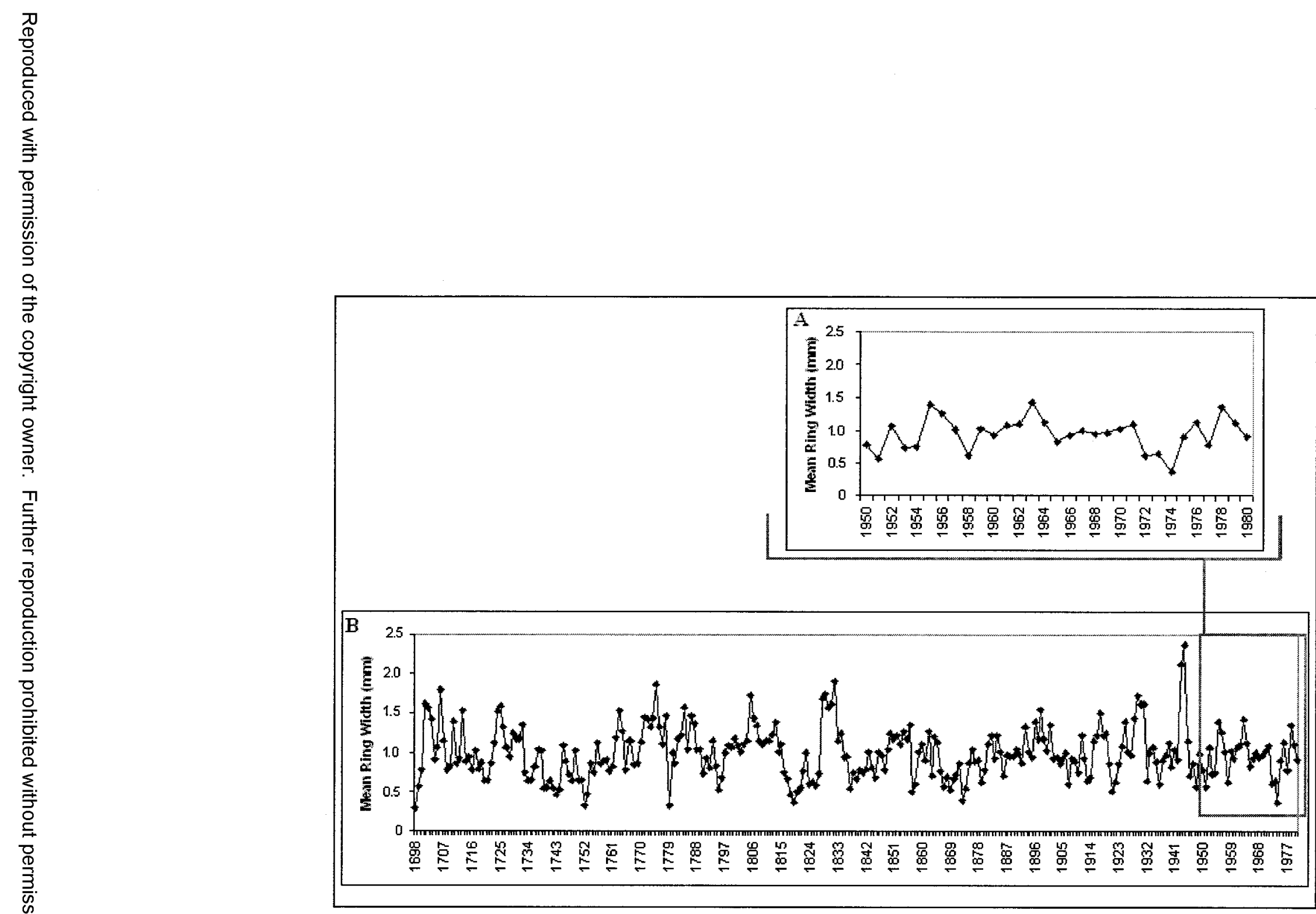

Fig 3. Effect of window of reference on the perception of environmental variation. A seemingly highly variable environment (A) appears less variable when compared to a longer history for the same site (B). 


\subsubsection{1a Temporal variation}

Fluctuations in animal populations have been intensively studied by ecologists. This field of study has lead to the accumulation of data tracking population stability, often gathered for conservation purposes. Since fluctuations in population are primarily driven by demographic and environmental stochasticity (Kendall and Fox, 2002, Weatherhead, et al., 2002), population data have the additional property of mapping the effects of changing climate on the organisms studied. Changes in climate directly impact the organism studied through altering the weather conditions in which it must live, as well as indirectly through impact on its food supplies. By determining the relationship between climate and population fluctuation, climate can be reconstructed from population numbers.

Studies have been conducted on levels of population variability (Pimm, 1984; Pimm and Redfearn, 1988), on characterization of the spectral colour of that variation (Inchausti and Halley, 2002) and on long-term trends of increasing variation (Pimm and Redfearn, 1988; Cyr, 1997; Bengtsson et al., 1997). The same data used in these studies could be used to quantify levels of site-specific environmental variance to address evolutionary questions.

The climate signal contained within this form of data can be difficult to interpret. Animals are by nature mobile; therefore, they tend to move to maintain an environment that suits their preference. While tracking numbers in a given population will give some indication of the effects of climate, the fact that animals tend to migrate in search of beneficial climates lessens the climate signal that can be detected through population fluctuations. 
Animal population time-series analyses also suffer from being short in duration, as these studies are effort intensive. Data obtained from these studies rarely extend more than a few seasons (and even more rarely across the numerous generations required to assemble an accurate picture of environmental variation) (Jassby and Powell, 1990; Goudie, 1992). Fluctuations detected within the populations studied represent a fragment of that population's history. In this situation, increase or decline of the population is a comparative concept (Shaffer, et al., 1998) and lacks the larger context of that population's history. If the population of study only recently moved into the region or grew to the present observed size at the beginning of the study due to a prolonged period of above average climate suitability, a return to a more normal state could be falsely interpreted as a population crash, where in fact the species was ill-suited to the norm for the region.

The short-term nature of these studies could potentially be offset through the use of natural history collections. These collections have been successfully used to analyse declines in plant and animal species across a wide range of scales, from single localities to large biotic and political regions (Shaffer, et al., 1998). While not as yet utilized for studies of evolutionary response to variable environments, these collections represent a potential source of biotic information on environmental stochasticity obtained through tracking the response of species to their changing environment.

\subsubsection{1b Spatial series}

Spatial time series, or tracking the changing biota of a given area over time, offer an alternative to tracking the sizes of individual populations. As these changes are often a response to environmental change, tracking the course of changing biota offers a proxy measure of climate change. Such time-series analyses are conducted using two different 
approaches. One approach involves the analysis of ecosystems by tracking the process of succession and species turnover. This first approach is restricted to a shorter timeframe, as few data sets are long-term in nature, with the exception of some long-term records of avian populations - such as those used by Russell, et al. (1995).

Tracking changes in the biotic structure of ecosystems is often linked to testing the island biogeography theory (McArthur and Wilson, 1967), and population theories, rather than directly studying variation itself (e.g., Russell, et al., 1995). The conservation movement has lead to a rapid increase in research into turnover (the change in composition of communities as a result of immigration and extinction; Russell, et al., 1995). Conservation efforts are often directed towards preserving the condition of an ecosystem in the state at which it was found. For this reason, conservation studies, as a by-product of attempting to preserve a constant state, detect and record changes in these same systems. These approaches share one similarity; they track changes in the populations existing in a given area over time. Data demonstrating such changes allow one to extrapolate from the population data and achieve some measure of how the abiotic environment is varying.

The second spatial approach involves reconstructing past climates through analysis of fossilized or otherwise captured remnants of past biota, to detect changes over vast time scales (providing data bases which stretch back over millennia). The field of sedimentology relies heavily upon the biotic remnants captured within layers of sediment. These biotic elements (and the isotopes contained within them) are key components for the dating of sediment layers. In addition to aiding in the dating of abiotic sediment layers, the biotic remnants in these layers also allow for the reconstruction of detailed climate characteristics during the period in which the sediments were deposited. In 
general, organisms exhibit widely varying environmental requirements. Different species require differing mean temperatures, levels of precipitation and even different substrates to survive in a given location. By determining what species assemblages were present in a region during a given period of time, it is possible to reconstruct the conditions under which they must have existed by cross-referencing the requirements of those species detected together (Goudie, 1992; Aaldberg and Litt, 1998; Sinka and Atkinson, 1999). As the environment changes over time, so too will the species assemblages, as species which are better adapted to the new conditions compete better for resources and exclude less well adapted species. Changes in the biota in turn indicate changes in the environment, and the changing species composition provides a continuous record of climate conditions in a given site. This concept forms the basis of several different fields of paleoclimate reconstruction.

Speaking of fossils commonly evokes images of large dinosaur bones. In addition to providing anatomical information, large fossils provide a record of long-term trends [such as extinction rates and, potentially cataclysmic events such as bolide impacts (Raup, 1991)] but, due to their rarity, are of limited use for climate reconstruction. Only a minute percentage of specimens from a population are preserved from the destructive effects of erosion and geological events. While large fossils allow the presence of an animal to be detected in a given region, the absence of large fossil remains means very little. Though these types of fossils have allowed for the detection of large scale extinction events (Raup, 1991), they are not appropriate for reconstructing shorter term aspects of climate variation required to test theories on the scale of intra-specific evolution. The dependence on ${ }^{14} \mathrm{C}$ analysis to date large fossil remains means that the 
time of death for a given fossil cannot be determined more accurately than to within thousands of years (Goudie, 1992).

The study of smaller fossils, from arthropods to microfossils such as pollen and diatoms, allows for a more detailed picture of past climate to be reconstructed (Elias and Matthews, 2002; Goodfriend, 1992; Harrowitz, 1989; and Sinka and Atkinson, 1999). These smaller fossils are more numerous than larger ones (some plants produce millions of pollen grains annually) and are more easily preserved in substrates than larger ones.

Small arthropods, Coleoptera in particular, have recently seen increased use in the reconstruction of past climates (Sinka and Atkinson, 1999). Insects such as Coleoptera can rapidly respond to changes in climate through migration. Their high mobility results in reduced lag between the climate event or situation leading to unsuitability and their subsequent emigration from the area. As Coleoptera have been studied in great detail, the environmental requirements of modern species are well documented. Through use of the Mutual Climate Range (MCR) method, detailed maps of past climate can be constructed by determining the overlapping niche requirements of species whose remains are found captured in substrates (Aalberberg and Litt, 1998; Sinka and Atkinson, 1999).

In a similar manner to that used with Coleoptera, pollen analysis (palynology) is used to reconstruct complex plant assemblies based on knowledge of the physiology and reproductive traits of pollen producing plants. Palynology is based on the fact that some sediments contain pollen grains, delivered primarily through the air as pollen rain (Harrowitz, 1989). Through comparing pollen output levels, as well as dispersal patterns, it is possible to determine the composition of the plant community at the time the sediment layer of interest was formed (Gribbon, 1978). The overlapping climate requirements for the plants contained within the assemblage can allow researchers to 
develop a fairly complete picture of climate at the time represented by the layer of soil in a similar manner to that used with Coleoptera in the MCR method. Horowitz (1989) reports a continuous pollen core from Israel extending 3.5 million years in length.

While palynological and Coleopteran MCR studies can produce detailed reconstructions of historic biota, and from them the climate conditions needed to sustain it, these studies are incapable of resolving the fine scale detail needed to produce a record of environmental variance on the scale required for testing evolution at the individual level.

The combination of easily disturbed substrates, lack of clear annual banding and subsequent reliance on ${ }^{14} \mathrm{C}$ dating all limit the application of the MCR method in evaluating bet-hedging traits.

\subsubsection{Layered deposits}

Snail shells (Goodfriend, 1992) and fish otoliths (Patterson, 1999) are alternative biotic indicators of climate (as in each case their growth is affected by environmental conditions) which have the advantage of continuously deposited layers. They are excellent measures of how variable their environments were during their growth, translating numerous abiotic and biotic variables into a single biotic measure and presenting that measure in the form of sequential rings (Goodfriend, 1992). In addition to the amount of growth displayed, the sequential rings of snail shells have been used to gain additional insight into their environment (Goodfriend, 1992; Goudie, 1992). ${ }^{13} \mathrm{C}$ values of organic matter in the shells have been used to reconstruct $\mathrm{C}_{4}$ plant distributions, from which rainfall can be inferred, while ${ }^{18} \mathrm{O}$ analysis of shell carbonate have allowed trends in the oxygen isotope composition of rainfall to be determined (Goodfriend, 1992). 
In spite of the wealth of data contained within the shells and otoliths, the mobile nature of snails and fish, both under their own power while alive and through considerable displacement along waterways after their death (Goodfriend, 1992), obscures the signal that could have been contained within them. The fact that they are so easily displaced after death makes it difficult to use their captured climate signal to make a statement about the level of variation intrinsic to the location in which they are discovered. An additional problem is that, due to their small size, multiple shells or otoliths must be used simultaneously in isotope analysis (Goodfriend, 1992). This requirement for multiple shells opens the possibility that shells selected for a single test may actually originate from different locations or time periods, rendering the information gleaned through isotope analysis suspect.

The short lifespan of snails and fish makes it impossible to construct continuous chronologies dating back significant distances in time. The only way to construct long term chronologies using these proxies is through ${ }^{14} \mathrm{C}$ dating or the dating of the substrates in which they are found. This dependence does not lend itself to the construction of the detailed chronologies needed to address bet-hedging theories.

Ice cores offer an alternative to fossil-based analysis. Ice contains a wealth of information about past climates. While the majority of ice core research is conducted at the poles, some research has also been done at high altitudes, where temperatures do not rise above freezing, allowing for the development of ice sheets much like those found at the poles (Thompson, 2000).

Ice sheets are formed through the steady accumulation of snow. During the summer, the alternating sun and darkness allow snow to warm and cool, forming a crust, while winter provides less opportunity for the snow to melt, resulting in a less dense layer 
of snow. These seasonal differences in snow accumulation result in annual bands of snow composed of two distinct forms. As snow falls each year, the preceding snow is compressed until it forms ice (Goudie, 1992; Castellano et al., 2004). These ice sheets, formed in regions that never experience melting temperatures, show clear annual banding.

As snow falls, small pockets of atmospheric air are captured within it. Dating of these layers is accomplished through isotope analysis of gases and organic matter trapped within the ice. These dates can be further checked through cross-referencing known dates, such as the sulphate-level analyses used to detect traces of major volcanic events, against their evidence in the ice layer that corresponds to their date of occurrence (Goudie, 1992; Castellano, et al., 2004). Isotope analysis of the contents of layers allows for temperature and atmospheric composition to be determined. Global air currents can also be determined through analysis of the pollen content trapped within the ice layers.

The Epica Dome C ice core, extracted from Antarctica, extends 1,000,000 years into the past (Castellano, et al., 2004). At this extreme age, however, the maximum resolution achieved is approximately decadal in scale due to the compressing action of the mass of ice above (Goudie, 1992). While more recent ice is easily identified at an annual scale, the information contained within ice cores is of limited use for testing bethedging traits. The combination of the isolation of the sites in which ice cores can be drilled, and the broad nature of the information they contain means that their insights into environmental variation lend themselves more to the analysis of large scale perturbations than to those of evolution at the within-species scale.

While abiotic layered substrates such as ice cores are an excellent source of captured climate information, a biotic record of climate has the advantage of showing the 
climate signal, reduced to its cumulative effect on the biotic community. If organisms that share a location with the source of a biotic signal respond similarly to changes in their climate, such a biotic climate record would be a far more powerful tool in evolutionary research as it would remove the necessity of compiling various abiotic signals and attempting to model their effect on a biotic specimen.

Tropical and subtropical reefs composed of scleractinian corals provide an excellent biological record of past climate variation (Felis and Pätzold, 2003). During growth, these corals produce annual bands of aragonite $\left(\mathrm{CaCO}_{3}\right)$ at millimetre to centimetre rates of annual growth (Felis and Pätzold, 2003). As these corals grow, they incorporate isotopic and elemental tracers into their structure. The presence of these components allows for the reconstruction of such factors as ocean temperature, hydrologic balance and ocean circulation from the growth layers (Felis and Pätzold, 2003).

The longest stable isotope based coral record extends back 347 years, and was obtained from the Galapagos region (Felis and Pätzold, 2003). While this record provides excellent annual resolution, as well as a timeframe significant for the study of bet-hedging traits, the limited range of coral growth, to tropical and sub-tropical regions, means that they are only suitable to provide a record of environmental variation for these regions. In addition to their latitudinal boundaries, the fact that corals are formed in the ocean means that the variation they experience is relevant only to organisms that share this habitat. For these reasons, coral-based data on environmental variance is limited in its usefulness in analyzing bet-hedging traits; what is needed is an alternative biotic measure with a wider global distribution. 


\subsection{Dendrochronology}

Trees are another source of archival climate data deposited in regular and easily distinguishable layers. First developed in the south-western United States during the early part of the $20^{\text {th }}$ century by A.E. Douglass, dendrochronology is the science of dating events in former periods through a comparative study of annual growth rings in trees. The approximate age of a temperate forest tree can be determined by counting the annual growth rings in the lower part of the trunk, typically done at breast height. The width of a ring corresponds strongly to resource availability during the year it was produced, especially the late-wood portion of the ring (although storage tissues can lead to some lag time in signalling) (Cook and Kairiukstis, 1990). Climatic conditions such as precipitation, temperature, sun exposure, etc. determine the amount of energy available to a tree, and tree ring growth thus provides a summary record of how favourable the environment was to growth during a given year (Fritts, 1976). Wide rings signify favourable growing conditions, absence of disease and pests, and favourable climatic conditions, while narrow rings indicate unfavourable growing conditions or climate. This technique has been used extensively to examine past and present climate conditions (with most of this work classified under the sub-discipline of dendroclimatology; Kienast and

Luxmoore, 1988; Briffa et al., 1990; Scuderi, 1990; Yasue et al., 1997; Meko and Baisan, 2001; Martinelli, 2004).

Dendrochronology relies on the construction of tree-ring chronologies as indicators of site conditions. These chronologies are required to contain a minimum of 10 cross-dated trees to reduce the potential impact of tree-specific variables on the environmental signal of the rings (Fritts, 1976). Cross-dating is a procedure involving matching ring-width variations and other structural characteristics among trees that have 
grown in the same area allowing for the identification of the exact year in which a given ring was formed. This technique has also allowed for the construction of continuous records of annual climate extending back thousands of years (one of the longest chronologies being based in Europe and containing 9,928 years of annual ring data (Becker et al., 1991). Cross-dating has allowed the inclusion of ancient cores (taken from historic buildings, drift wood and even charcoal) in extended chronologies.

The International Tree-Ring Databank (ITRDB) was established in 1974 and its primary purpose is to provide a permanent location for the storage of well-dated, highquality dendrochronological data from around the world. The database was first developed and housed by the Laboratory of Tree-Ring Research, The University of Arizona until 1990, when the Paleoclimatology Program of the National Oceanic and Atmospheric Administration (NOAA) took over the operation of the ITRDB with the establishment of the World Data Center - A for Paleoclimatology at the National Geophysical Data Center (NGDC) in Boulder, Colorado, USA (Grissino-Mayer, 2005). This center houses many different types of paleoclimatic data, such as ice core, sedimentary, tree-ring, palaeobiological, pollen, and documentary data. Since its inception, the ITRDB has established itself firmly in the scientific community as one of the premier paleoclimatic databases (Grissino-Mayer, 2005). The ITRDB presently contains over 6,000 data sets, including 2,804 raw measurement files and 3,275 tree-ring chronologies. These data represent collections taken from over 1,500 sites around the world, and consist of over 100 tree and shrub species (Grissino-Mayer, 2005).

Tree rings record responses to a wider range of climatic variables, over a larger part of the Earth, than any other type of annually dated proxy record; in essence, every tree is a fixed weather station, recording the cumulative effect of environmental factors in 
that place over the life span of the tree. While individual trees alone can provide multicentury records, the ability to cross-date trees allows for the construction of detailed annual (even seasonal) environmental records extending thousands of years into the past. The combination of time period and detail covered by tree-rings suggests that they are ideally suited to the study of environmental variation.

Tree rings have been used to construct detailed climate histories extending back thousands of years. This natural catalogue of environmental change has great potential in providing a framework of the factors affecting the evolution of bet-hedging characteristics in herbaceous plants. More than any other currently used measure of environmental variance, tree rings have the potential to provide the biotic measure of site specific environmental variance that is needed to address problems associated with research into evolutionary response to variable environments. 


\section{Chapter II}

\section{Dendrochronology as a tool for quantifying environmental variation for use in life-history analyses}




\subsection{Introduction}

A basic quality of all natural environments is their variability. The level to which an organism is adapted to cope with this intrinsic variability in part determines its fitness. Because environments vary unpredictably, life history strategies that minimize the variation in fitness over generations, even at the expense of maximizing short-term fitness, are expected to evolve (Gillespie, 1976).

Bet-hedging theory seems well suited to explain apparently sub-optimal lifehistory strategies frequently observed in plants, animals, and fungi. Bet-hedging strategies maximize success over longer time scales than those associated with maximizing fitness during a single generation. The validity of any model of optimality thus depends on the time-scale over which selection is acting (Simons and Johnston, 2003). Testing bet-hedging is a labour intensive project, requiring extended study in order to examine both environmental variation and its effect on evolution. Because longterm observation of natural populations - potentially on a decadal or longer time-scale would be required to detect the benefit of an observed "sub-optimal" life history trait (Simons and Johnston, 2003), such bet-hedging studies are rarely conducted.

A potential alternative to this approach involves quantifying the historical variation of sites, then examining how the species within these sites have evolved to cope with that level of variation. While many techniques exist that can provide histories of environmental variation (see chapter I), these techniques are incapable of providing detailed site-specific environmental variation as experienced by the in-site biota on a scale appropriate for life-history analyses. To successfully quantify the historical variation of sites, a technique is required that can provide a cumulative measure of the many sources of environmental variation as they relate to their impact on the fitness of 
the biota. It was concluded in Chapter I that tree rings may represent just such a cumulative measure. The physiological process that is involved in the development of annual rings in trees is directly regulated by environmental conditions during the time of formation (Fritts, 1976). Measurements of environmental conditions have shown that trees respond immediately to changes in their environment and the sum of these minute changes is expressed in an annual growth ring (Fritts, 1976). Degree days, precipitation, cloud cover, as well as numerous additional variables are merged into a single quantifiable representation of the 'quality' of a given growing season.

Tree-rings have been used, within the science of dendrochronology, to construct detailed climate histories extending back thousands of years. While they have never been used to compare site-specific levels of environmental variation, these natural catalogues of environmental change have great potential to provide a framework of factors affecting the evolution of life-history strategies.

In Chapter I, I argued that tree-ring analysis offers a potentially ideal tool to quantify the natural variance under which life history strategies such as bet-hedging are selected for. Tree ring analysis has the potential to fill the void caused by a lack of an accurate, biotic measure of real-world environmental variation and how it selects for life history strategies. In this chapter, I test the suitability of dendrochronology for the task of detecting site specific environmental variation.

\subsection{The Study}

Year-to-year variation within sites is readily detectable through dendrochronological analysis (Chapter 1). This study aims first to develop methods to quantify this sitespecific environmental variation, and then to ask whether differences in this environmental variation can be found among geographical locations across Eastern North 
America. To accomplish this, I make use of the International Tree-ring Databank to analyse a total of 48 populations of two tree species with roughly coincident ranges.

Although the main thrust is to detect differences in historical environmental variation, a secondary goal is to detect trends in site-specific environmental variation along gradients in latitude, longitude, and altitude. I expect naturally occurring trends in mean ring-width to exist across these geographic gradients due to the moderating effect of climate clines on tree growth. Season length in Eastern North American tends to decrease with increasing latitude and with increasing altitude; therefore it should be possible to detect changes in both mean ring-width and environmental variation along these gradients, and to ask whether environmental variation increases with shorter season length. In addition, the moderating effect of the Atlantic Ocean on climate is expected to result in decreased levels of site-specific environmental variation at lower longitudes (closer to the coast).

If the techniques of dendrochronology successfully distinguish between site based on their profiles of environmental variation, this represents a novel tool for investigating environmental variation that can be directly applied to studying the evolution of life history traits.

\subsection{Methods}

\subsubsection{Species and site selection}

The study was conducted using two species of gymnosperm [Tsuga canadensis (Eastern Hemlock) and Pinus strobus (White Pine)], both of which are native to NorthEastern North America and have similar ranges (Fig. 4). Species selection was based on several criteria. The first criterion was that the trees used be responsive to - and their ring widths provide a clear signal for - environmental fluctuations. Conifers are recognized as 
providing a "sensitive" as opposed to "complacent" series, meaning they show a greater signal to noise ratio for environmental factors (Fritts and Swetnam, 1989). In general then, variations in conifer ring-widths more accurately portray changes in environmental factors than those in deciduous trees.

The second criterion used in species selection was the availability of site data for a given species in the International Tree-ring Database (ITRDB). While many species are contained within the database, only a few species have been extensively sampled in the area of interest. T. canadensis and P. strobus are both present in the database in sufficient volume (34 and 13 sites respectively) to allow their usage for the study of patterns of environmental variation.

Once the species of interest were narrowed to the 2 used, the available data sets were examined to determine a time span over which data from all sites for a given species are available. The time periods selected were 1800-1980 for T. canadensis and 19001970 for $P$. strobus. A minimum sample of 20 trees whose chronologies covered the entire time span selected for that species was required for a site to be included in the study (the ITRDB standard requires a minimum sample of 10 trees per site; NCDCP, 2005). This was done to have a more representative sample of growth at the site.

In addition to the data obtained from the ITRDB, one site was added through field sampling of 21 individual $P$. strobus at the National Resources Canada - Petawawa Research Forest. An attempt to core T. canadensis at this same site produced cores of poor quality which were not suitable for dating. The $P$. strobus cores were extracted using a hand held $5 \mathrm{~mm}$ increment borer to remove 2 cores along the radius of each tree at breast height. The 2 cores were drawn from opposite sides of each tree and parallel to any perceived ground slope to avoid compression wood. The collection of 2 cores from 


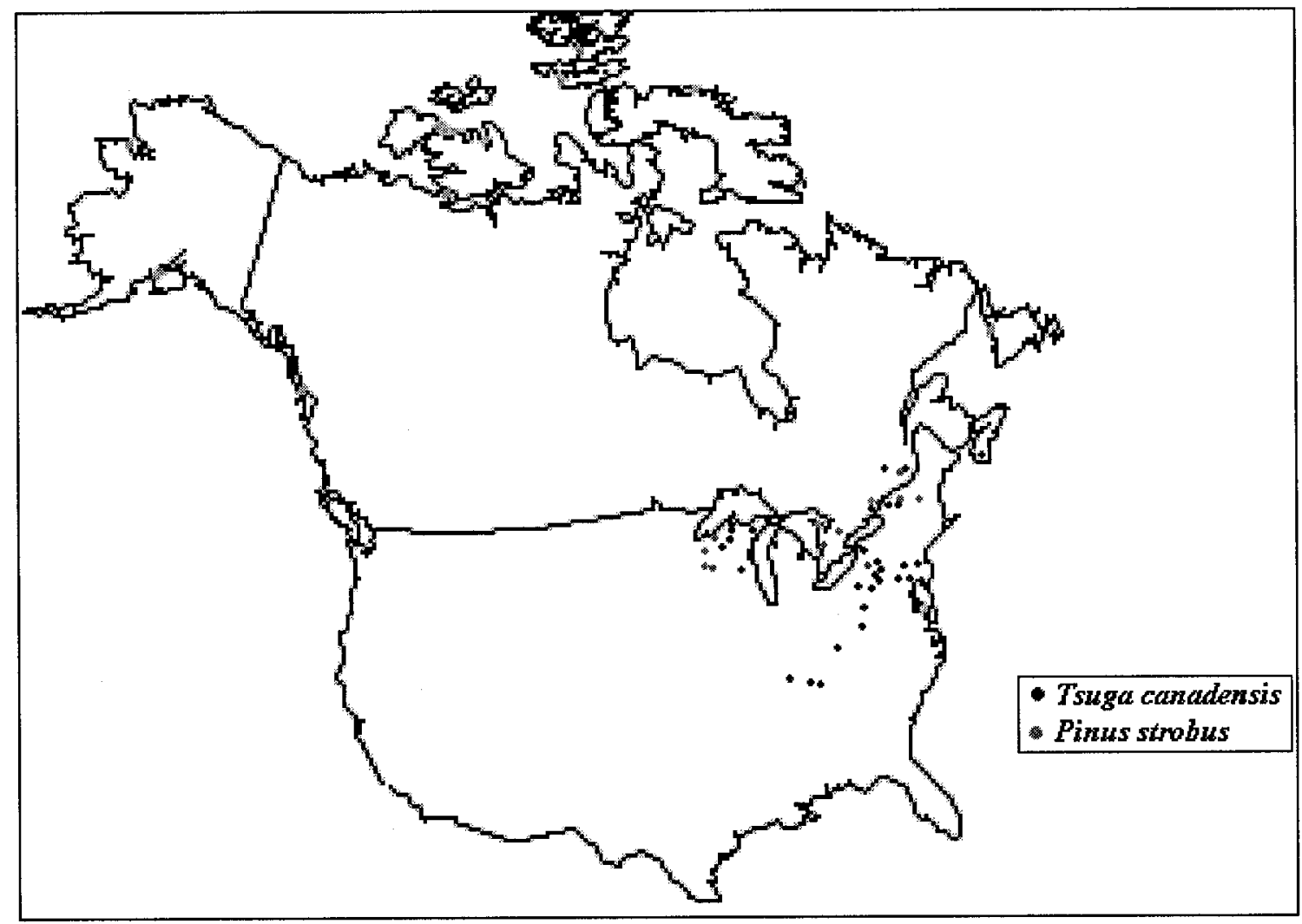

Fig 4. Location of study sites in Eastern North America (coordinates found in tables 1 \& 2). 
each tree facilitates the dating of rings and reduces the impact of growth abnormalities localized to a small portion of the circumference of the tree. The cores were then mounted (following techniques described by Fritts, 1976) and allowed to air dry. Once dry, the cores were progressively sanded using first 80 -grit, then 220-grit sandpaper to obtain a smooth, flat surface which allowed precise measurement of annual rings.

A Unislide stage assembly, Accu-Rite linear encoder, and Metronics QC$10 \mathrm{~V}$ digital readout were used in conjunction with MeasureJX software to measure the ring-widths of tree cores collected at Petawawa.

\subsubsection{Transformation of data}

Raw ring-width values for $34 T$. canadensis and $13 P$. strobus sites were obtained from the INTRDB. The quality of all ring series data was ensured through the use of COFECHA software to increase the confidence of cross-dating and measurement accuracy. Data from all sites were then detrended using the program ARSTAN to remove age-related growth trends and endogenous stand effects. ARSTAN and COFECHA are freely downloadable programs available through the ultimate tree ring web page developed and maintained by Henry Grissino-Mayer.

The program ARSTAN produces chronologies from tree-ring measurement series by detrending and indexing (standardizing) the series. ARSTAN applies a curve to the data - using either negative linear or logarithmic regression - fit determined by the program - to remove long term natural biological growth trends in ring width (as a tree ages the rings produced are smaller and smaller) and then applies a smoothing spline to remove the effect of non-environmental growth effects such as growth spurts caused by release from competition, due to, for example, neighbour blow-down. For the purpose of this study, a 50\% smoothing spline was selected to minimize the amount of 
environmental signal lost, while at the same time minimizing the amount of nonenvironmental noise contained within the ring measurements (Yasue, et al., 1997).

Because the study also requires the use of trends in actual ring width, I did not wish to index data through use of ARSTAN. Each ring width, after indexing, would be presented as a percentage of the mean ring width for the site as opposed to an actual measurement. Series were therefore detrended using ARSTAN, but without indexing, so as to preserve the mean and variance characteristics of the raw ring widths (Cook, 2003 personal communication). As indexing is not an optional step in the program, I bypassed this step (Cook, 2003 - personal communication) by dividing the raw ring-width data from each site by the detrending curves produced by ARSTAN. These curves are an optional output of the program. By using ARSTAN to produce detrending curves, then applying them to the raw ring-width data, it was possible to obtain detrended data sets still in metric measurement format.

\subsubsection{Data analysis}

Coefficients of variation have long been an accepted comparative measure of trait variation (Sokal and Bauman, 1980). Since variation in tree growth might not scale with mean ring-width, an alternative method of correcting for mean growth across sites was also used in the study. This method involved taking the residuals from a variance in ringwidth versus mean ring width relationship of all the trees included in the study. The distance of residuals from "expected" variance at a given mean ring width, as estimated by the best fit regression, was used as a measure of site-specific environmental variation.

A comparison of the inter-year variation in ring width of all cores from all sites was made for each tree species. An ANOVA was used to detect significant differences in variation across sites within a species. A post-hoc Tukey's HSD test, which corrects for 
multiple comparisons, was then performed to test for differences between all pairs of sites.

To obtain a single measure of the environmental variation characteristic of each site, a Representative Site Tree (RST) was compiled using the mean ring widths for each year contained within the chronology (producing a single ring-series representing the average growth of the stand in each year). This single RST provided an indicator of the overall variability of that site, but statistical analyses were performed using individuallevel data.

\subsection{Results}

\subsubsection{Detecting site-specific differences in environmental variation}

Dendrochronological analyses allowed for the detection of differences in mean ring-width $(M R W)$ variation across sites in both Tsuga canadensis and Pinus strobus (Tables 1-4, Fig. 5-6). A significant positive relationship was detected between mean ring-width and variance in ring-width in both species studied (Fig. $7 \& 8$ ).

Coefficients of variation and residuals from a mean ring-with/variance plot were used to correct for differences in mean ring-width amongst sites and provide a measure of site specific environmental variation. In Tsuga canadensis and Pinus strobus, significant differences in levels of environmental variation between sites were detected using both the coefficients of variation and residual-based measures (Tables $3 \& 4$ ).

Using the coefficient of variation to correct for differences in mean ring-width $(M R W)$ significant differences in levels of site-specific environmental variation (SSEV) between different $T$. canadensis and $P$. strobus sites were detected (Tables $3 \& 4$ ). 
Performing a Tukey's HSD test on the results of an ANOVA performed on coefficients of variation $(\mathrm{CV}), 8$ levels of variation were detectable in Tsuga canadensis (Table 5), while 5 levels of variation were detectable in Pinus strobus (Table 6).

Using residuals as an alternative method of correcting for differences in $M R W$, significant differences in variance in year to year ring growth in both $T$. canadensis and P. strobus were detected (Tables $3 \& 4$ ). When Tukey's HSD test was performed on ANOVA residuals from a $M R W /$ variance plot, 4 levels of variation were detected in $T$. canadensis (Table 5) and 2 levels in P. strobus (Table 6).

A greater number of differences among sites in environmental variation were detectable using $C V$ to correct for differences in $M R W$, compared to the residual-based measure (Tables $5 \& 6$ ); however, a significant relationship remains between the calculated coefficient of variation and mean ring-width in both species sampled (Fig. $7 \& 8)$ :

T. canadensis: $R^{2}=0.1717, p<0.001$;

P. strobus: $R^{2}=0.0837, p<0.001$.

As a further comparison of the methods used to correct for differences in $M R W$, figures 6 and 7 demonstrate how the two methods of correcting for $M R W$ rank sites based on the level of environmental variation detected in both T. canadensis and $P$. strobus. The ranked order of the sites is similar from $C V$ to residual based measure in $T$. canadensis (Fig. 5A to 5B) and P. strobus (Fig. 6A to 6B). These figures show that, in most cases, the two methods used rank sites in similar order based on levels of SSEV.

\subsubsection{Testing for trends in environmental variation}

To determine whether or not the differences in SSEV could be explained by site, simple regressions of location, latitude, longitude, and altitude were performed against 
the measured levels of SSEV. Significant relationships were found in T. canadensis between $C V$ and latitude $\left(R^{2}=0.0412, P<0.01\right)$, between $C V$ and longitude $\left(R^{2}=0.010\right.$, $P<0.01)$ and between $C V$ and altitude $\left(R^{2}=0.001, P=0.01\right)$. Using residuals to calculate $S S E V$, significant relationships were detected for $T$. canadensis with latitude $\left(R^{2}=0.016\right.$, $P<0.01)$, longitude $\left(R^{2}=0.025, P<0.01\right)$, and altitude $\left(R^{2}=0.007, P=0.01\right)$.

Repeating the above comparisons using $P$. strobus, significant relationships were detected with latitude $\left(R^{2}=0.196, P<0.01\right)$ and longitude $\left(R^{2}=0.233, P<0.01\right)$ using $C V$ to measure SSEV. When using residuals, the only significant relationship detected was between $S S E V$ and longitude $\left(R^{2}=0.012, P=0.04\right)$.

Since the 3 "location" variables (latitude, longitude, and altitude) are not completely independent - sites located further south tend to be located at higher elevation (Tables 2 \& 3), a relationship especially relevant in $T$. canadensis (Fig. 9) - a multiple linear regression of latitude, longitude and altitude was performed on both measures of SSEV (Tables $7 \& 8$ ). The multiple linear regression was capable of explaining very little of the detected levels of SSEV in Tsuga canadensis - overall $R^{2}=0.054$ (Table 7). The multiple linear regression on $T$. canadensis showed that the strongest parameter effect was that associated with latitude (partial $R^{2}=0.038$ using $C V$ and partial $R^{2}=0.018$ for the residual-based measure - Table 7). Neither measure was capable of detecting a significant parameter estimate for the effect of altitude (Table 7).

The simple linear regressions explained little of the trends in variance in mean ring-width and the variables used were shown not to be independent in nature, so multiple linear regressions were performed on $T$. canadensis and $P$. strobus using both the $\mathrm{CV}$ and residuals to correct for differences in mean ring-width. 
Table 1. A listing of Tsuga canadensis sites used in this study, all site data drawn from the ITRDB.

\begin{tabular}{|c|c|c|c|c|c|c|c|}
\hline Site Name & $\begin{array}{l}\text { Latitude } \\
\text { (Deg. N) }\end{array}$ & $\begin{array}{l}\text { Longitude } \\
\text { (Deg. W) }\end{array}$ & $\begin{array}{c}\text { Altitude } \\
\text { (m) }\end{array}$ & $\begin{array}{c}\text { Variance } \\
\text { in Mean } \\
\text { Ring- } \\
\text { Width }\end{array}$ & $\begin{array}{c}\text { Mean } \\
\text { Ring } \\
\text { Width } \\
\text { (mm) } \\
\end{array}$ & $\begin{array}{c}C V- \\
\text { Based } \\
\text { Measure }\end{array}$ & $\begin{array}{c}\text { Residuals } \\
\text {-Based } \\
\text { Measure }\end{array}$ \\
\hline Alan Seeger & 40.7 & 77.7 & 200 & 0.469 & 1.031 & 0.664 & -1.581 \\
\hline Alger County & 46.3 & 86.6 & 250 & 0.800 & 1.019 & 0.878 & 2.102 \\
\hline Bass Lake Peninsula & 45.1 & 88.9 & 400 & 0.853 & 1.097 & 0.842 & 0.212 \\
\hline Bigelow Pond & 42 & 73.2 & 500 & 1.434 & 1.035 & 1.156 & 7.922 \\
\hline Bowater Mersey & 44.8 & 64 & 100 & 0.829 & 1.053 & 0.865 & 1.331 \\
\hline Dingman's Falls & 41.2 & 74.9 & 250 & 0.464 & 1.002 & 0.680 & -0.737 \\
\hline East Branch & 41.3 & 77.7 & 250 & 0.346 & 1.036 & 0.567 & -2.984 \\
\hline Ferncliff Nat Rsv & 39.8 & 79.7 & 250 & 0.468 & 1.021 & 0.670 & -1.300 \\
\hline Gibb's Brook & 44.2 & 71.4 & 750 & 0.707 & 1.085 & 0.775 & -0.868 \\
\hline Granville Gulf & 44 & 72.8 & 500 & 0.537 & 1.004 & 0.730 & -0.058 \\
\hline Hemlock Cove & 37.5 & 79.5 & 750 & 0.632 & 1.101 & 0.722 & -2.122 \\
\hline Hemlock Nat Area & 40.2 & 77.7 & 250 & 0.514 & 1.072 & 0.668 & -2.418 \\
\hline Kelsey's Tract & 35.1 & 83.2 & 1000 & 1.274 & 1.132 & 0.997 & 3.328 \\
\hline Kit Springs & 35.3 & 83.9 & 1300 & 0.128 & 1.006 & 0.356 & -4.206 \\
\hline Loon Lake & 46.2 & 89.3 & 500 & 0.886 & 1.033 & 0.911 & 2.505 \\
\hline Mohonk Lake & 41.8 & 74.2 & 200 & 0.381 & 1.043 & 0.592 & -2.830 \\
\hline Mt. Rogers & 36.7 & 81.7 & 500 & 0.338 & 1.032 & 0.564 & -2.935 \\
\hline North 40 Tract & 41 & 73 & 500 & 1.115 & 1.054 & 1.002 & 4.177 \\
\hline Pack Forest & 43.5 & 73.8 & 200 & 0.756 & 1.019 & 0.853 & $\| .641$ \\
\hline Presque Isle & 46.7 & 90 & 200 & 0.629 & 1.071 & 0.741 & -1.211 \\
\hline Ramsey's Draft & 38.3 & 79.3 & 700 & 0.497 & 1.070 & 0.659 & -2.498 \\
\hline Reed Pond & 46.2 & 69 & 250 & 0.941 & 0.999 & 0.971 & 4.131 \\
\hline Ricket's Glen S.Park & 41.4 & 76.3 & 250 & 0.421 & 1.035 & 0.627 & -2.179 \\
\hline Riviere Moulin & 46.6 & 71.9 & 100 & 0.756 & 1.044 & 0.832 & 0.865 \\
\hline $\begin{array}{l}\text { Roaring Brook Keene } \\
\text { Valley }\end{array}$ & 44.1 & 73.8 & 250 & 0.673 & 1.011 & 0.812 & 1.082 \\
\hline Rock Rift & 41 & 74 & 200 & 0.429 & 1.019 & 0.643 & -1.626 \\
\hline Salt Point & 46.5 & 84.9 & 250 & 0.787 & 1.061 & 0.836 & 0.652 \\
\hline Salt Springs & 41.9 & 75.9 & 500 & 0.793 & 1.020 & 0.873 & 1.998 \\
\hline Savage Gulf & 35.5 & 85.6 & 1000 & 0.572 & 0.979 & 0.772 & 1.038 \\
\hline Silver River & 46.7 & 88.8 & 300 & 0.861 & 1.068 & 0.869 & 1.187 \\
\hline Spruce Glen & 41.8 & 74.2 & 200 & 0.594 & 1.051 & 0.733 & -0.973 \\
\hline Sweet Root & 39.8 & 78.5 & 250 & 0.468 & 1.016 & 0.673 & -1.150 \\
\hline Tionesta Natural Area & 41.8 & 79 & 700 & 0.347 & 1.021 & 0.577 & -2.493 \\
\hline
\end{tabular}


Table 2. A listing of Pinus strobus sites used in this study, all site data drawn from the ITRDB except Petawawa, which was field-sampled.

\begin{tabular}{|c|c|c|c|c|c|c|c|}
\hline Site Name & $\begin{array}{l}\text { Latitude } \\
\text { (Deg. N) }\end{array}$ & $\begin{array}{l}\text { Longitude } \\
\text { (Deg. W) }\end{array}$ & $\begin{array}{l}\text { Altitude } \\
\text { (m) }\end{array}$ & $\begin{array}{c}\text { Variance in } \\
\text { Mean Ring- } \\
\text { Width }\end{array}$ & $\begin{array}{l}\text { Tean Ring- } \\
\text { Width } \\
\text { (mm) }\end{array}$ & $\begin{array}{c}C V-\text { Based } \\
\text { Measure }\end{array}$ & $\begin{array}{c}\text { Residuals - } \\
\text { Based } \\
\text { Measure }\end{array}$ \\
\hline Petawawa & 46 & 77.5 & 118 & 2.816 & 2.494 & 0.673 & -0.255 \\
\hline Dividing Lake Aquatic & 45.4 & 78.6 & 500 & 2.615 & 0.972 & 1.665 & -1.503 \\
\hline Lonfellow Trail & 41 & 79 & 400 & 7.036 & 1.037 & 2.558 & 2.964 \\
\hline Presque Isle River & 46.7 & 90 & 200 & 4.840 & 1.093 & 2.013 & 0.805 \\
\hline $\begin{array}{l}\text { White Pine Hollow } \\
\text { Forest Preserve }\end{array}$ & 42.6 & 91.1 & 320 & 5.637 & 1.010 & 2.352 & 1.545 \\
\hline Blufton & 43.4 & 91.9 & 335 & 1.614 & 0.962 & 1.321 & -2.511 \\
\hline Backbone State Park & 42.6 & 91.6 & 335 & 4.846 & 0.991 & 2.222 & 0.741 \\
\hline $\begin{array}{l}\text { Soper Brook West } \\
\text { Branch }\end{array}$ & 46 & 69.3 & 400 & 4.594 & 1.031 & 2.080 & 0.517 \\
\hline Basin Pond & 44.5 & 70.1 & 420 & 2.293 & 0.994 & 1.524 & -1.810 \\
\hline $\begin{array}{l}\text { Acadia National Park } \\
\text { Stand-8 }\end{array}$ & 44.3 & 68.3 & 67 & 5.847 & 0.989 & 2.445 & 1.741 \\
\hline $\begin{array}{l}\text { Acadia National Park } \\
\text { Stand-6 }\end{array}$ & 44.4 & 68.3 & 9 & 4.308 & 0.977 & 2.125 & 0.193 \\
\hline $\begin{array}{l}\text { Wilmington Notch - } \\
\text { Roaring Brook }\end{array}$ & 44.3 & 73.9 & 750 & 2.433 & 1.034 & 1.508 & -1.642 \\
\hline $\begin{array}{l}\text { Winch Pond - } \\
\text { Adirondack Mountains }\end{array}$ & 44.3 & 73.9 & 800 & 2.443 & 0.962 & 1.625 & -1.682 \\
\hline Hobbs Lake & 46.7 & 80.2 & 500 & 4.966 & 1.042 & 2.139 & 0.896 \\
\hline
\end{tabular}


Table 3. Results from ANOVAs on differences in variation using coefficient of variation to correct for mean ring-width.

\begin{tabular}{|c|c|c|c|c|c|}
\hline \multicolumn{6}{|c|}{ Tsuga canadensis } \\
\hline Source & DF & Sum of Squares & Mean Square & F Ratio & P Value \\
\hline$\overline{\text { Model }}$ & $\overline{33}$ & 2.664 & 0.081 & 7.4178 & $<0.01$ \\
\hline Error & 894 & 9.789 & 0.011 & & \\
\hline \multicolumn{6}{|c|}{ Pinus strobus } \\
\hline Source & DF & Sum of Squares & Mean Square & F Ratio & P Value \\
\hline$\overline{\text { Model }}$ & $\overline{13}$ & 18.289 & 1.415 & $\overline{133.3611}$ & $<0.01$ \\
\hline Error & 340 & 3.606 & 0.011 & & \\
\hline
\end{tabular}


Table 4. Results from ANOVAs on differences in variation using residuals to correct for mean ring-width.

\begin{tabular}{|c|c|c|c|c|c|}
\hline \multicolumn{6}{|c|}{ Tsuga canadensis } \\
\hline Source & $\underline{D F}$ & Sum of Squares & Mean Square & F Ratio & P Value \\
\hline$\overline{\text { Model }}$ & $\overline{33}$ & 33012.360 & 1000.37 & $\overline{6.236}$ & $<0.01$ \\
\hline Error & 894 & 142410.480 & 160.41 & & \\
\hline \multicolumn{6}{|c|}{ Pinus strobus } \\
\hline Source & DF & Sum of Squares & Mean Square & F Ratio & P Value \\
\hline$\overline{\text { Model }}$ & $\overline{13}$ & 0.604 & 0.046 & $\overline{2.293}$ & $\overline{<0.01}$ \\
\hline Error & 340 & 6.893 & 0.020 & & \\
\hline
\end{tabular}


Table 5. Tsuga canadensis sites ranked according to differences in coefficients of variation (A) and residuals $(B)$. Significant differences in levels of variation calculated using Tukey's HSD test.

\begin{tabular}{|c|c|c|c|c|c|c|c|c|}
\hline \multirow{2}{*}{$\begin{array}{l}\text { (A) Site } \\
\text { Bigelow Pond }\end{array}$} & \multicolumn{2}{|c|}{ Level } & \multirow{2}{*}{$\begin{array}{r}\begin{array}{c}\text { Lst. Sq. } \\
\text { Mean }\end{array} \\
0.55\end{array}$} & \multirow{2}{*}{$\begin{array}{l}\text { (B) Site } \\
\text { Bigelow Pond }\end{array}$} & \multicolumn{3}{|c|}{ Level } & \multirow{2}{*}{$\begin{array}{l}\begin{array}{l}\text { Lst. Sq. } \\
\text { Mean }\end{array} \\
16,99\end{array}$} \\
\hline & A & & & & \multicolumn{3}{|l|}{$\mathrm{A}$} & \\
\hline North 40 Tract & A B & & 0.52 & North 40 Tract & \multicolumn{3}{|l|}{ A } & 16.93 \\
\hline Bowater Mersey & A B & $\mathrm{C}$ & 0.49 & $\begin{array}{l}\text { Riviere Du } \\
\text { Moulin }\end{array}$ & \multicolumn{3}{|l|}{ A B } & 7.46 \\
\hline $\begin{array}{l}\text { Riviere Du } \\
\text { Moulin }\end{array}$ & \multicolumn{2}{|c|}{ A B C } & 0.48 & Bowater Mersey & \multicolumn{3}{|c|}{ A B C } & 6.73 \\
\hline Bass Lake Pen. & \multicolumn{2}{|c|}{ A B C D } & 0.48 & Reed Pond & \multicolumn{3}{|c|}{ A B C } & \multirow{2}{*}{$\begin{array}{l}6.11 \\
5.51\end{array}$} \\
\hline Reed Pond & \multicolumn{2}{|c|}{ A B C D E } & 0.46 & Number 3 Pond & \multicolumn{3}{|c|}{ A B C D } & \\
\hline Number 3 Pond & \multicolumn{2}{|c|}{ A B C D E F } & 0.46 & Bass Lake Pen. & \multicolumn{3}{|c|}{ B C D } & 3.73 \\
\hline Gibbs's Brook & \multirow{2}{*}{\multicolumn{2}{|c|}{ 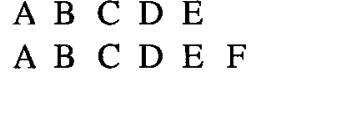 }} & 0.46 & Savage Gulf & \multicolumn{3}{|c|}{ B C D } & 3.12 \\
\hline Kelsey's Tract & & & 0.45 & $\begin{array}{l}\text { Roaring Brook } \\
\text { K.V. }\end{array}$ & \multicolumn{3}{|c|}{ B C D } & 2.90 \\
\hline Presque Isle & \multirow{2}{*}{$\begin{array}{l}\text { B } \\
\text { B }\end{array}$} & $C D E F$ & 0.44 & Pack Forest & B & C & D & 2.48 \\
\hline Loon Lake & & $C D E F G$ & 0.43 & Granville Gulf & B & $\mathrm{C}$ & D & 1.70 \\
\hline Silver River & B & $\mathrm{C} D \mathrm{DE} G$ & 0.43 & Salt Springs & B & $\mathrm{C}$ & D & 0.53 \\
\hline Pack Forest & B & $\mathrm{CDEFG}$ & 0.42 & Gibbs's Brook & B & $\mathrm{C}$ & D & 0.19 \\
\hline Salt Springs & B & $C D E F G$ & 0.42 & Alan Seeger & B & $\mathrm{C}$ & D & -0.34 \\
\hline $\begin{array}{l}\text { Roaring Brook } \\
\text { K.V. }\end{array}$ & & C D E F G & 0.42 & Loon Lake & B & $\mathrm{C}$ & D & -0.43 \\
\hline Savage Gulf & B & C D E F G & 0.41 & $\begin{array}{l}\text { Ferncliffe Nat. } \\
\text { Rsv. }\end{array}$ & B & $\mathrm{C}$ & D & -0.87 \\
\hline Granville Gulf & & $C D E F G$ & 0.41 & Rock Rift & B & $\mathrm{C}$ & D & -1.05 \\
\hline Salt point & & C D E F G & 0.41 & $\begin{array}{l}\text { Sweet Root Nat. } \\
\text { Ar. }\end{array}$ & B & $\mathrm{C}$ & D & -1.18 \\
\hline Alger County & & C D E F G & 0.40 & Alger County & B & $\mathrm{C}$ & D & -1.34 \\
\hline Hemlocks Nt. Ar. & & C D E F G H & 0.40 & Presque Isle & B & $\mathrm{C}$ & $\mathrm{D}$ & -1.60 \\
\hline $\begin{array}{l}\text { Sweet Root Nt. } \\
\text { Ar. }\end{array}$ & & $\mathrm{CDEFGH}$ & 0.40 & Dingman's Falls & B & $\mathrm{C}$ & D & -1.92 \\
\hline Spruce Glen & & C D E F G H & 0.40 & Ricket's Glen & B & $\mathrm{C}$ & $\mathrm{D}$ & -2.08 \\
\hline Ricket's Glen & & C D E F G H & 0.39 & Silver River & B & $\mathrm{C}$ & $\mathrm{D}$ & -2.33 \\
\hline $\begin{array}{l}\text { Ferncliffe Nat. } \\
\text { Rsv. }\end{array}$ & & C D E F G H & 0.39 & Kelsey's Tract & B & C & $\mathrm{D}$ & -2.57 \\
\hline Alan Seeger & & C D E F G H & 0.39 & Mount Rogers & B & $\mathrm{C}$ & D & -2.67 \\
\hline Mount Rogers & & C D E F G H & 0.39 & Salt point & & $\mathrm{C}$ & D & -3.67 \\
\hline Rock Rift & & $\mathrm{CDEFGH}$ & 0.38 & $\begin{array}{l}\text { Hemlocks Nat. } \\
\text { Ar. }\end{array}$ & & $\mathrm{C}$ & $\mathrm{D}$ & -4.97 \\
\hline Dingman's Falls & & $\mathrm{DEF} F \mathrm{H}$ & 0.37 & Spruce Glen & & $\mathrm{C}$ & D & -4.98 \\
\hline Hemlock Cove & & E F $G \mathrm{H}$ & 0.36 & East Branch & & $\mathrm{C}$ & D & -6.24 \\
\hline East Branch & & E $F \quad G H$ & 0.35 & Mohonk Run & & $\mathrm{C}$ & D & -6.75 \\
\hline Ramsey's Draft & & F G H & 0.34 & Hemlock Cove & & & D & -6.83 \\
\hline Mohonk Run & & F G H & 0.34 & Kit Springs & & $\mathrm{C}$ & D & -6.99 \\
\hline Tionesta Nat. Ar. & & G H & 0.32 & Ramsey's Draft & & & D & -7.60 \\
\hline Kit Springs & & H & 0.29 & Tionesta Nat. Ar. & & & D & -8.05 \\
\hline Levels not sharing & ters ar & significantly differ & & Levels not sharing & ers are & sig. & & rent \\
\hline
\end{tabular}


Table 6. Pinus strobus sites ranked according to differences in coefficients of variation (A) and residuals $(B)$. Significant differences in levels of variation were calculated using Tukey's HSD test.

A

\begin{tabular}{|c|c|c|}
\hline$\underline{\text { Site }}$ & Level & $\begin{array}{l}\text { Lst. Sq. } \\
\text { mean }\end{array}$ \\
\hline Backbone State Park & A & 1.03 \\
\hline Acadia Nat. Pk. St. - 6 & $B C D$ & 0.411 \\
\hline Blufton & B & 0.406 \\
\hline Acadia Nat. Pk. St. - 8 & $B C D$ & 0.398 \\
\hline Hobbs Lake & $B C D$ & 0.387 \\
\hline $\begin{array}{l}\text { White Pine Hollow Frst. } \\
\text { Prsv. }\end{array}$ & B C & 0.378 \\
\hline Presque Isle River & $B C D$ & 0.339 \\
\hline Wilmington Notch - R.B. & B C D & 0.311 \\
\hline Winch Pond - Ad. Mnts & C D & 0.31 \\
\hline Soper Brook West Branch & C D & 0.301 \\
\hline Longfellow Trail & $C D$ & 0.297 \\
\hline Dividing Lake Aquatic & D & 0.293 \\
\hline Basin Pond & $C D E$ & 0.282 \\
\hline Petawawa & $\mathrm{E}$ & 0.197 \\
\hline
\end{tabular}

B

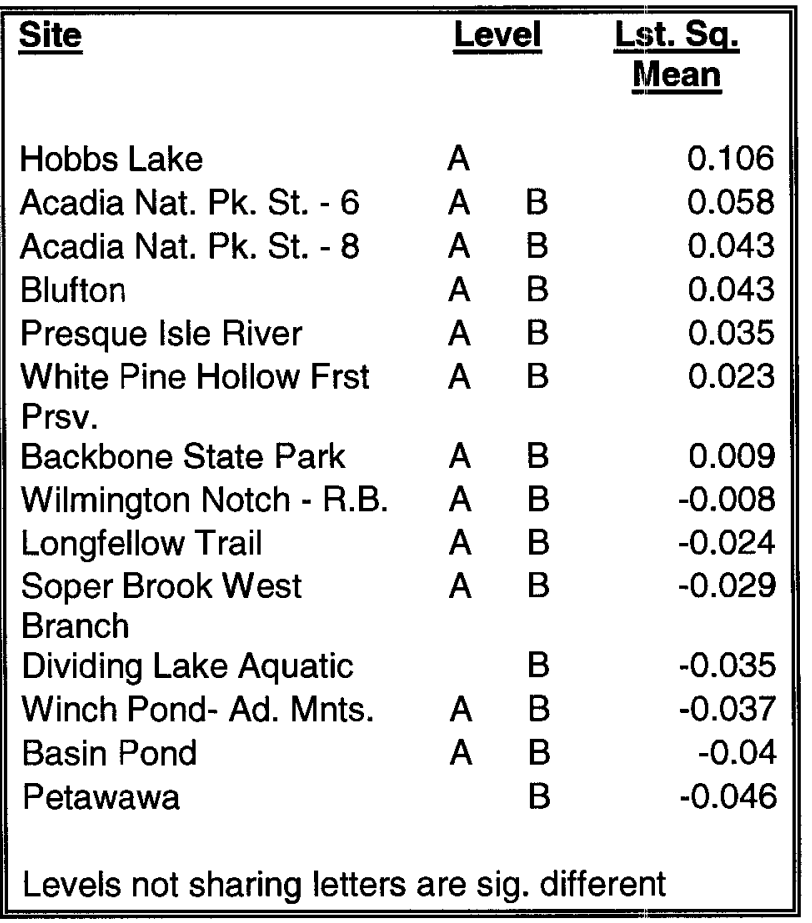




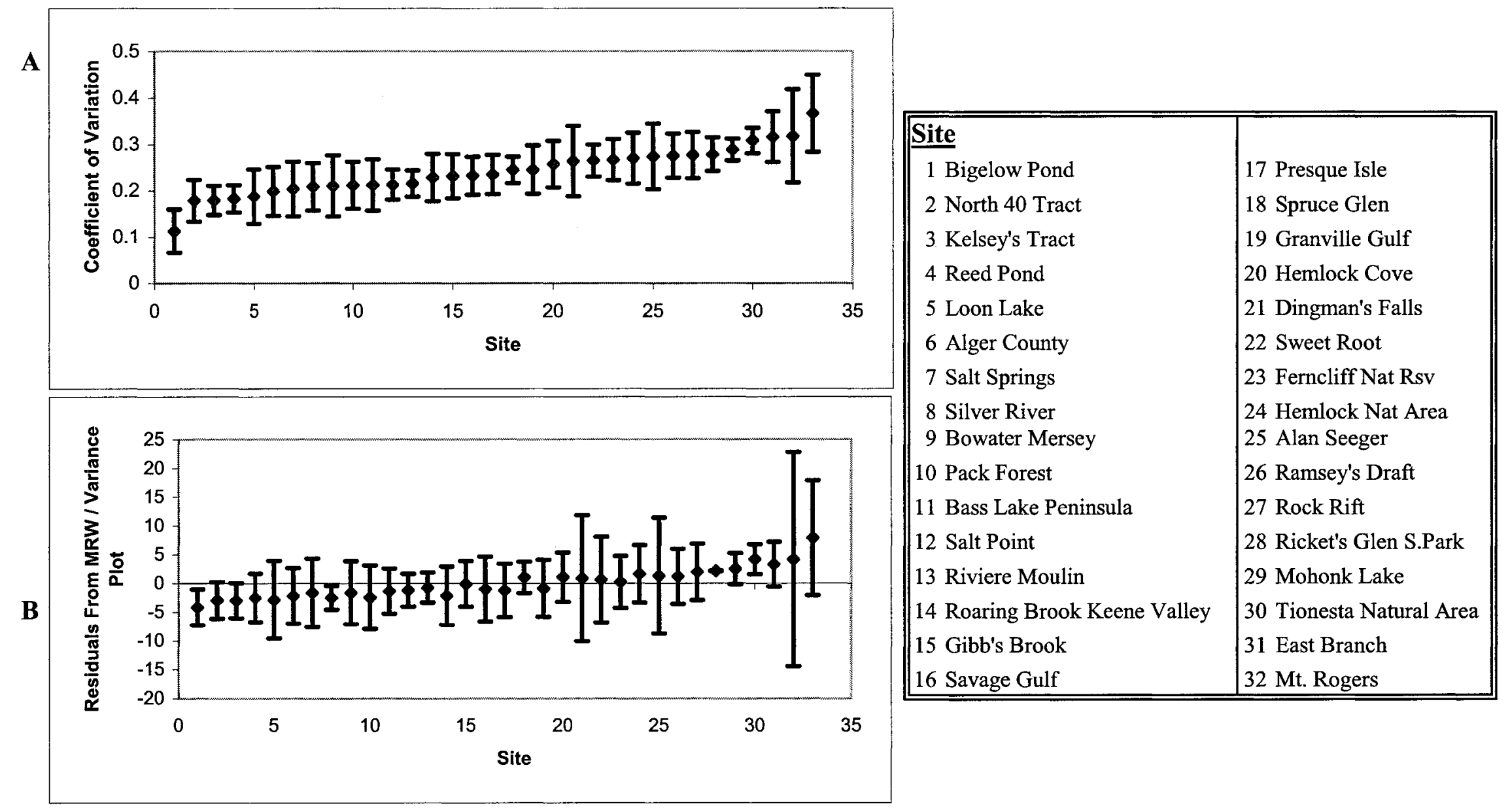

Fig 5. Levels of site-specific environmental variation in Tsuga canadensis as measured using coefficients of variation (A) and residuals (B). CV is ranked in increasing order.

Error bars are equal to one SD. 

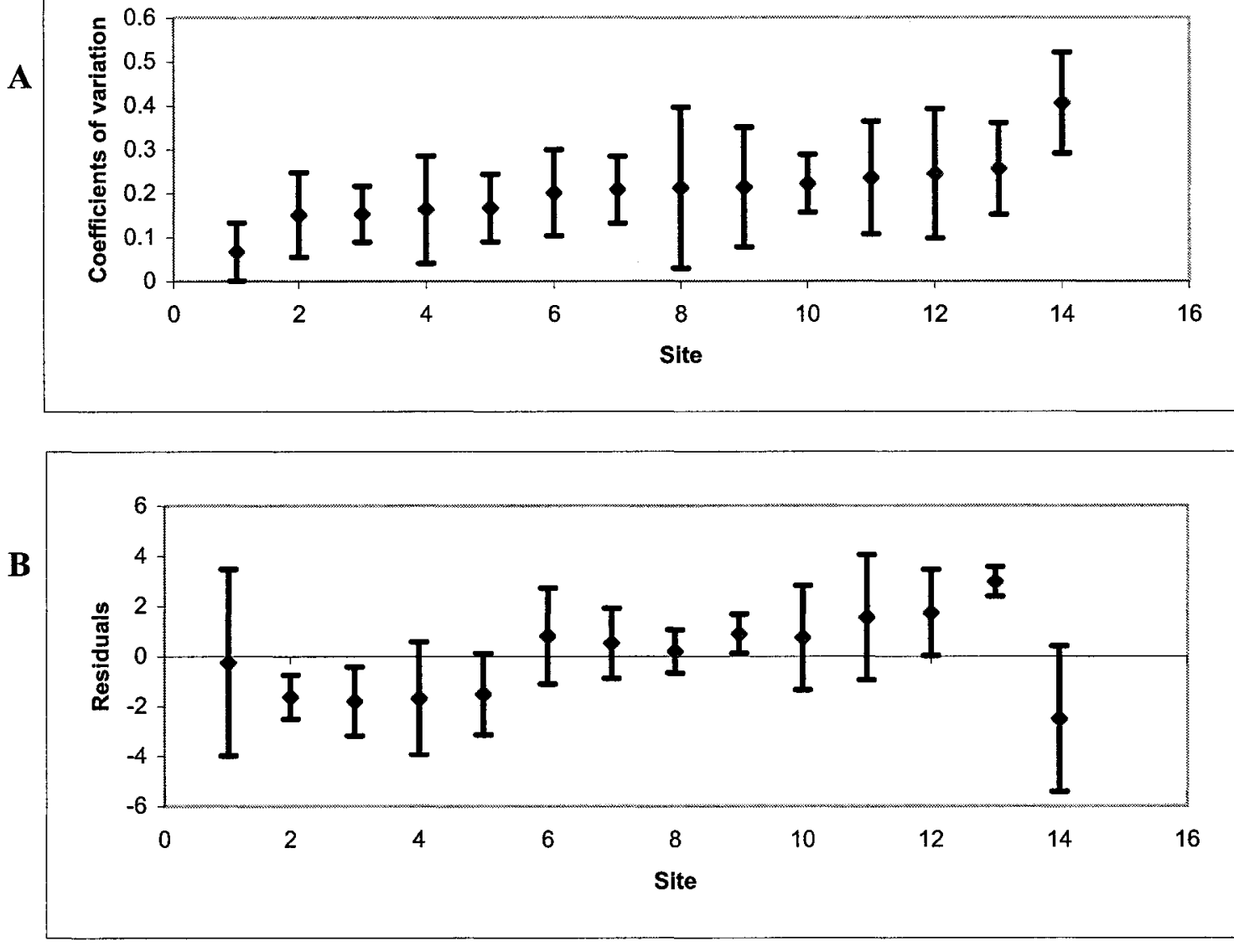

Fig 6. Levels of site-specific environmental variation in Pinus strobus as measured using coefficients of variation (A) and residuals (B). $C V$ is ranked in increasing order. Error bars are equal to one SD.

\begin{tabular}{|l|}
\hline$\underline{\text { Site }}$ \\
1 Blufton \\
2 Lonfellow Trail \\
3 Acadia National Park Stand-8 \\
4 White Pine Hollow Forest Preserve \\
5 Backbone State Park \\
6 Hobbs Lake \\
7 Acadia National Park Stand- 6 \\
8 Soper Brook West Branch \\
9 Presque Isle River \\
10 Dividing Lake Aquatic \\
11 Winch Pond - Adirondack Mountains \\
12 Basin Pond \\
13 Wilmington Notch Roaring Brook \\
14 Petawawa \\
\hline
\end{tabular}


A

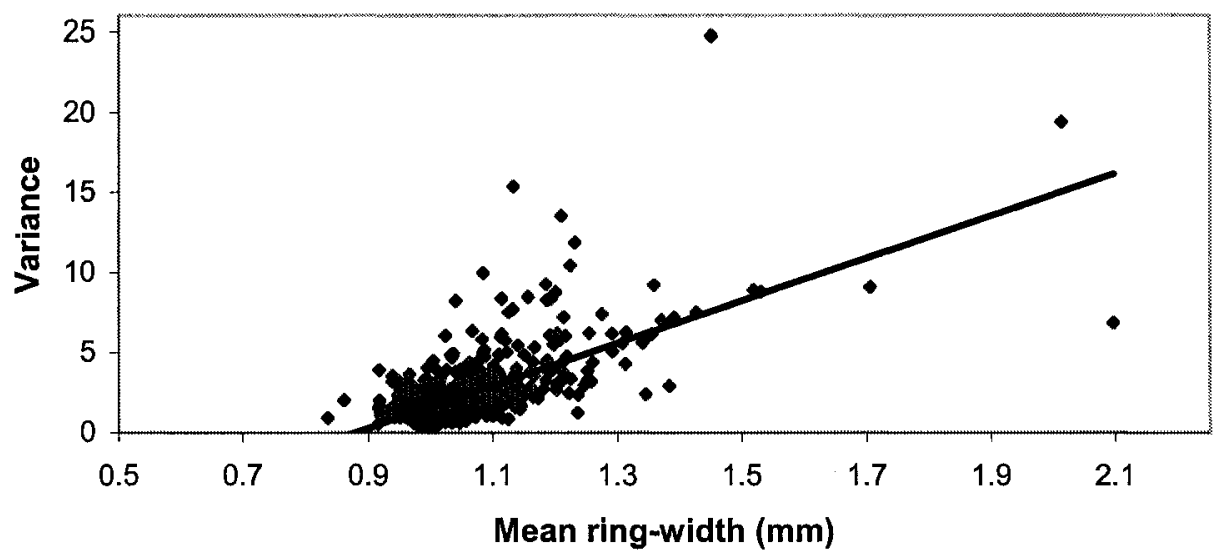

$R^{2}=0.450$

$P<0.01$

B

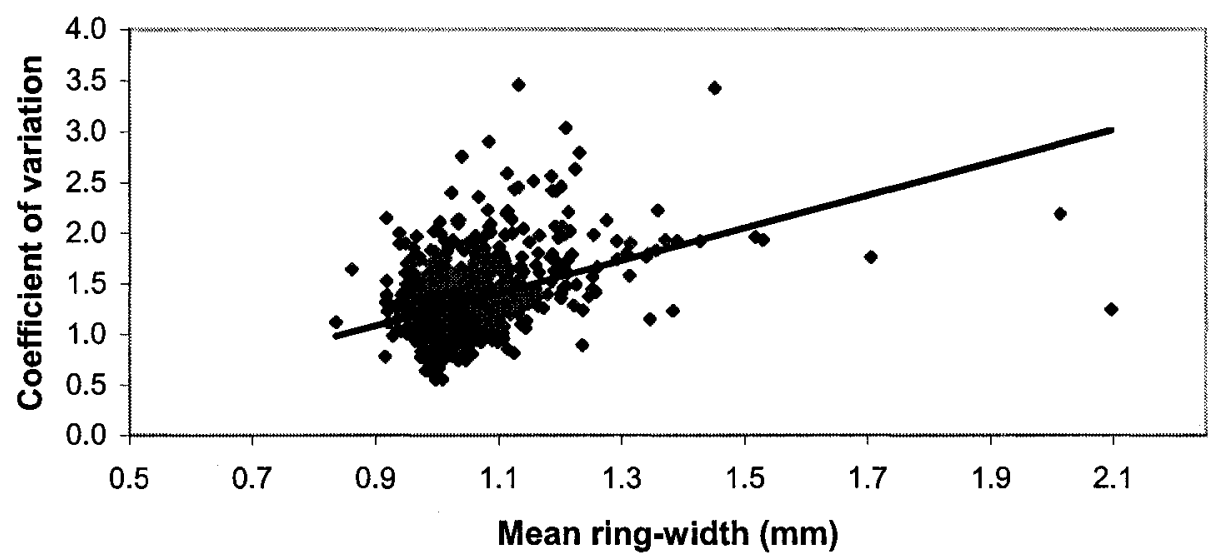

$R^{2}=0.171$

$P<0.01$

C

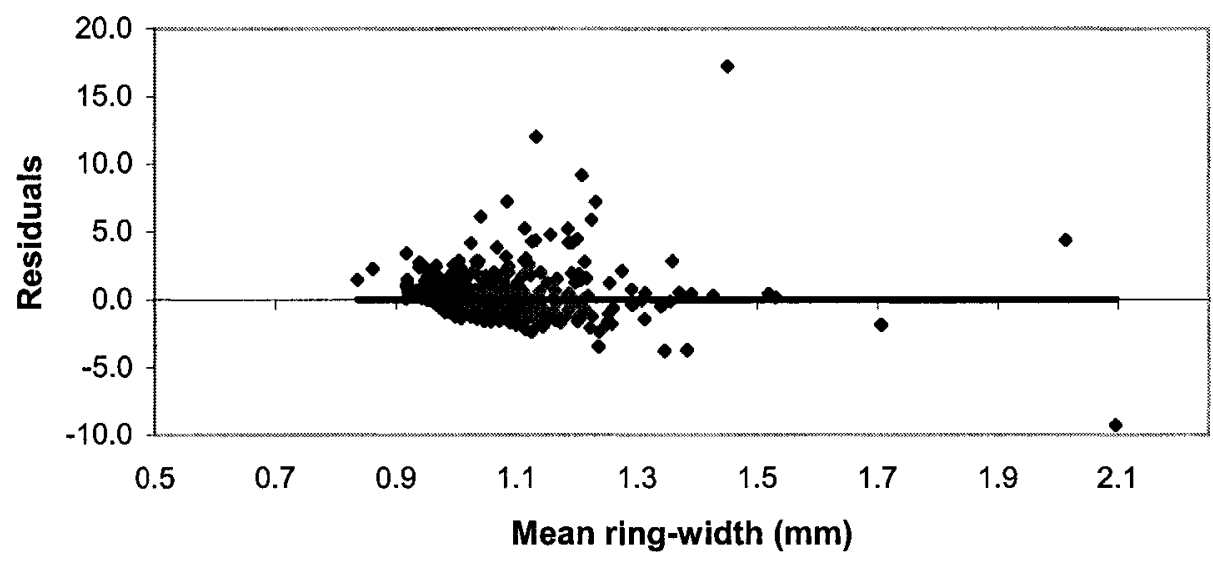

$R^{2}=0.000$

$P=1$

Fig 7. Tsuga canadensis - the relationship between mean and variance (A), as well as both methods of correcting for mean - Coefficient of Variation (B), and Residuals (C). 
A

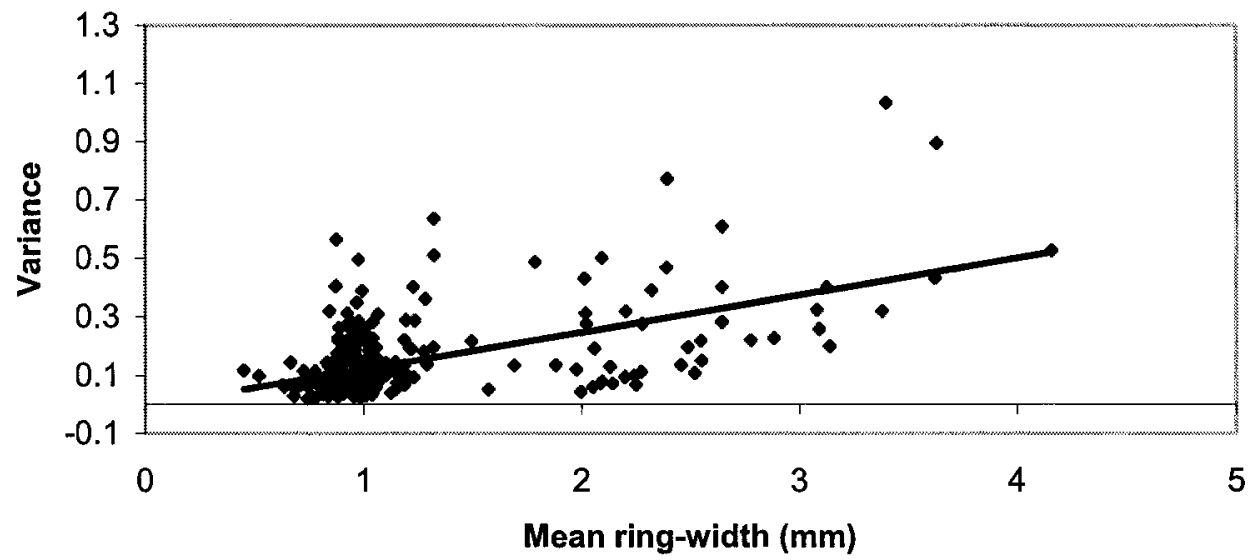

$R^{2}=0.208$

$P<0.01$

B

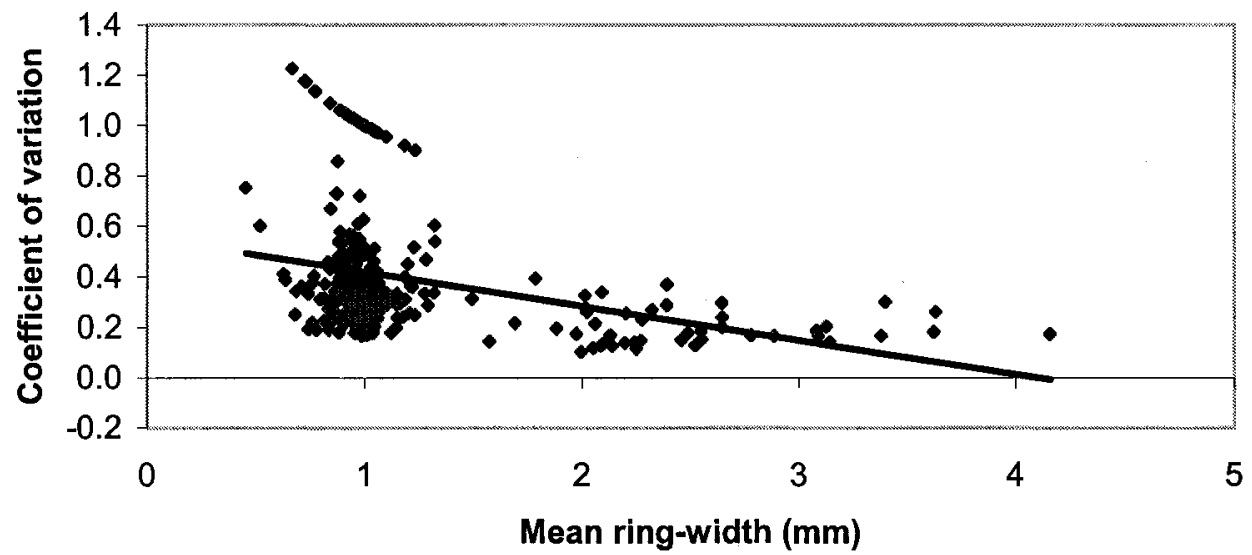

$R^{2}=0.084$

$P<0.01$

C

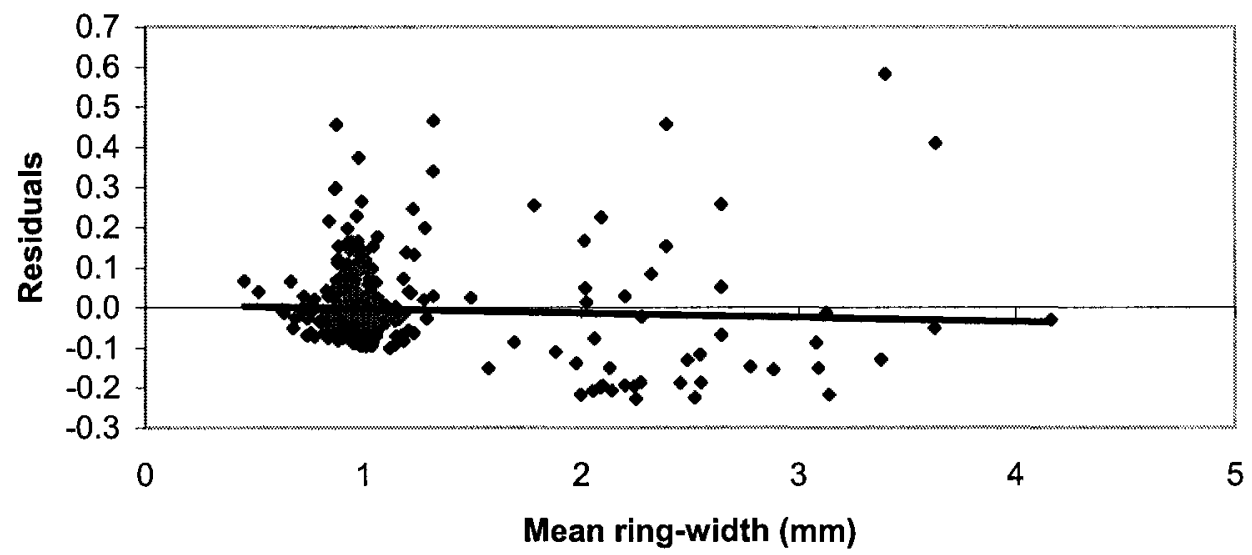

$R^{2}=0.003$

$P=0.33$

Fig 8. Pinus strobus - the relationship between mean and variance (A), as well as both methods of correcting for mean - Coefficient of Variation (B), and Residuals (C). 


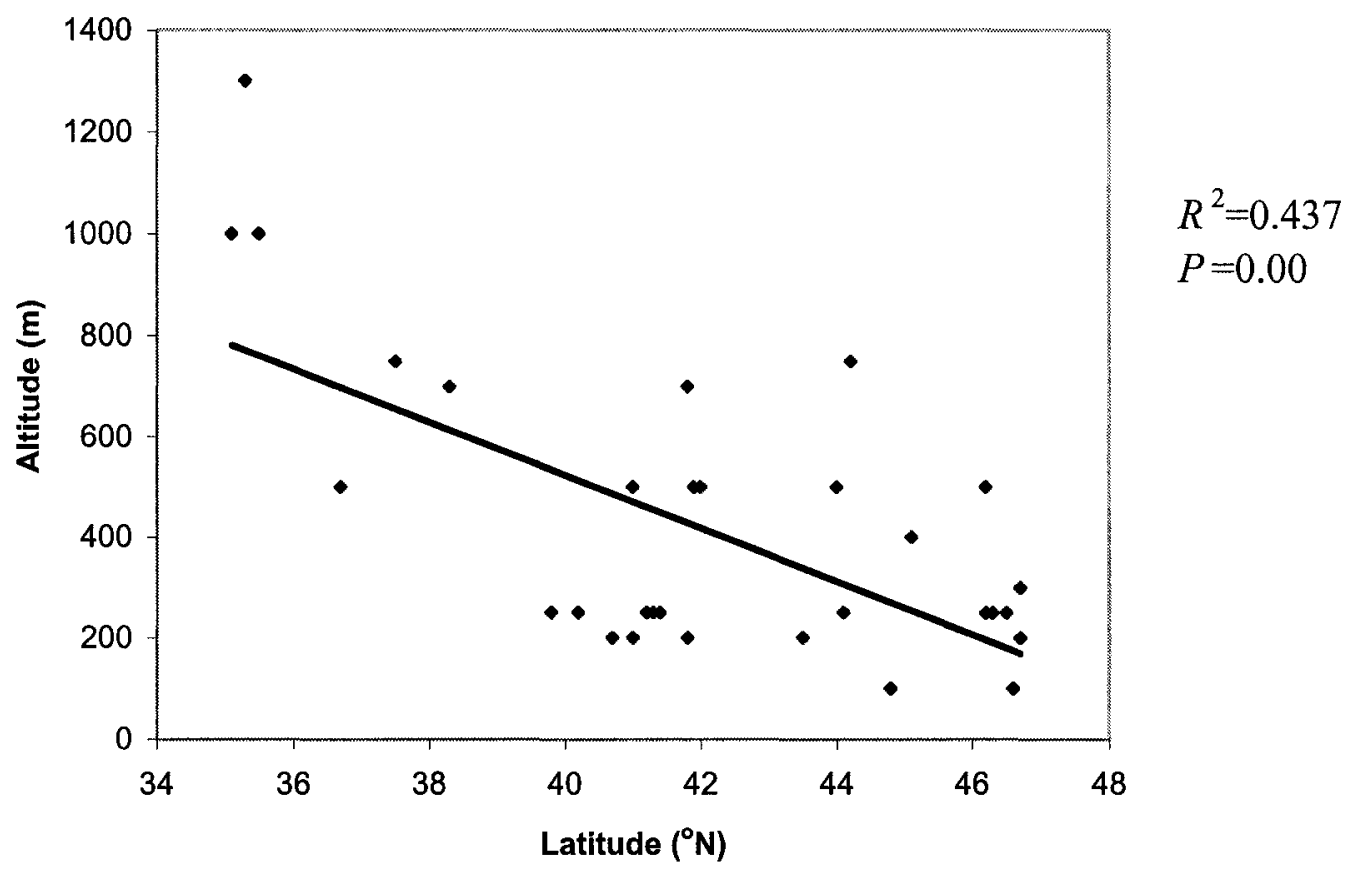

Fig 9. Relationship between latitude and altitude in determining site location in Tsuga canadensis . 
Table 7. Parameter estimates from a multiple linear regression on the effects of site location on levels of environmental variation as detected by ringgrowth in Tsuga canadensis.

\begin{tabular}{|c|c|c|c|c|c|}
\hline Coefficient of Variation & Estimate & $\frac{\text { Std. }}{\text { Error }}$ & T Ratio & $\frac{\text { Partial }}{\text { R-square }}$ & Prob $>t$ \\
\hline Latitude & 0.0087165 & 0.001467 & 5.94 & 0.038 & $<0.01$ \\
\hline Longitude & -0.002221 & 0.000627 & -3.54 & 0.013 & $<0.01$ \\
\hline Altitude & 0.0000357 & 0.000019 & 1.9 & 0.004 & 0.06 \\
\hline R Square & 0.054723 & & & & \\
\hline Residuals & Estimate & $\underline{\text { Std. }}$ & T Ratio & Partial & Prob $>t$ \\
\hline & & Error & & R-square & \\
\hline Latitude & 0.7188777 & 0.176012 & 4.08 & 0.018 & $<0.01$ \\
\hline Longitude & -0.393583 & 0.07523 & -5.23 & 0.03 & $<0.01$ \\
\hline Altitude & 0.0039958 & 0.00225 & 1.78 & 0.003 & 0.08 \\
\hline R Square & 0.044285 & & & & \\
\hline
\end{tabular}


Table 8. Parameter estimates from a multiple linear regression on the effects of site location on levels of environmental variation as detected by ring-growth in Pinus strobus.

\begin{tabular}{|c|c|c|c|c|c|}
\hline Coefficient of Variation & Estimate & $\frac{\text { Std. }}{\text { Error }}$ & TRatio & $\underset{\text { P-squartial }}{\text { P-sare }}$ & Prob $>t$ \\
\hline Latitude & -0.047069 & 0.007755 & -6.07 & 0.105 & $<0.01$ \\
\hline Longitude & 0.0102856 & 0.001474 & 6.98 & 0.139 & $<0.01$ \\
\hline Altitude & -0.000056 & 0.000057 & -0.98 & 0.003 & $<0.01$ \\
\hline R Square & 0.306204 & & & & \\
\hline Residuals & Estimate & Std. & T Ratio & Partial R- & Prob $>t$ \\
\hline Latitude & & Error & & square & \\
\hline Latitude & 0.0025013 & 0.005392 & -0.87 & 0.001 & 0.64 \\
\hline Longitude & 0.001934 & 0.001025 & 1.89 & 0.01 & 0.06 \\
\hline Altitude & -0.000037 & 0.00004 & -0.94 & 0.002 & 0.34 \\
\hline R Square & 0.015792 & & & & \\
\hline
\end{tabular}


In $P$. strobus, the multiple linear regressions using $C V$ explained more of the trend in variation in mean ring-width $\left(R^{2}=0.306\right)$ than that resulting from the use of residuals $\left(R^{2}=0.016\right.$ - Table 8$)$, though none of the parameter estimates from the use of residuals were significant. Using $\mathrm{CV}$ to correct for mean ring-width, the multiple linear regression showed relatively strong parameter effects for latitude $\left(R^{2}=0.105\right.$ and Longitude $\left(R^{2}=0.139\right)$ and very little for altitude $\left(R^{2}=0.003-\right.$ Table 8$)$.

Tests were next conducted to determine whether or not differences in SSEV could be explained by the proximity of sites to one another. Pair-wise distance analyses in $T$. canadensis revealed that while significant $(P=0.02)$, the correlation between differences in $C V$ and site proximity was very weak $\left(R^{2}=0.008-\right.$ Fig. 10$)$. The same analyses using absolute differences in the residual measure of SSEV showed no significant relationship $(P=0.40-$ Fig. 10).

Repeating the same analyses on $P$. strobus showed no significant relationship between site proximity and either absolute difference in $C V$ or in absolute difference in residuals, though the $C V$ based measure was almost significant $(P=0.08$ - Fig. 11$)$. 
A

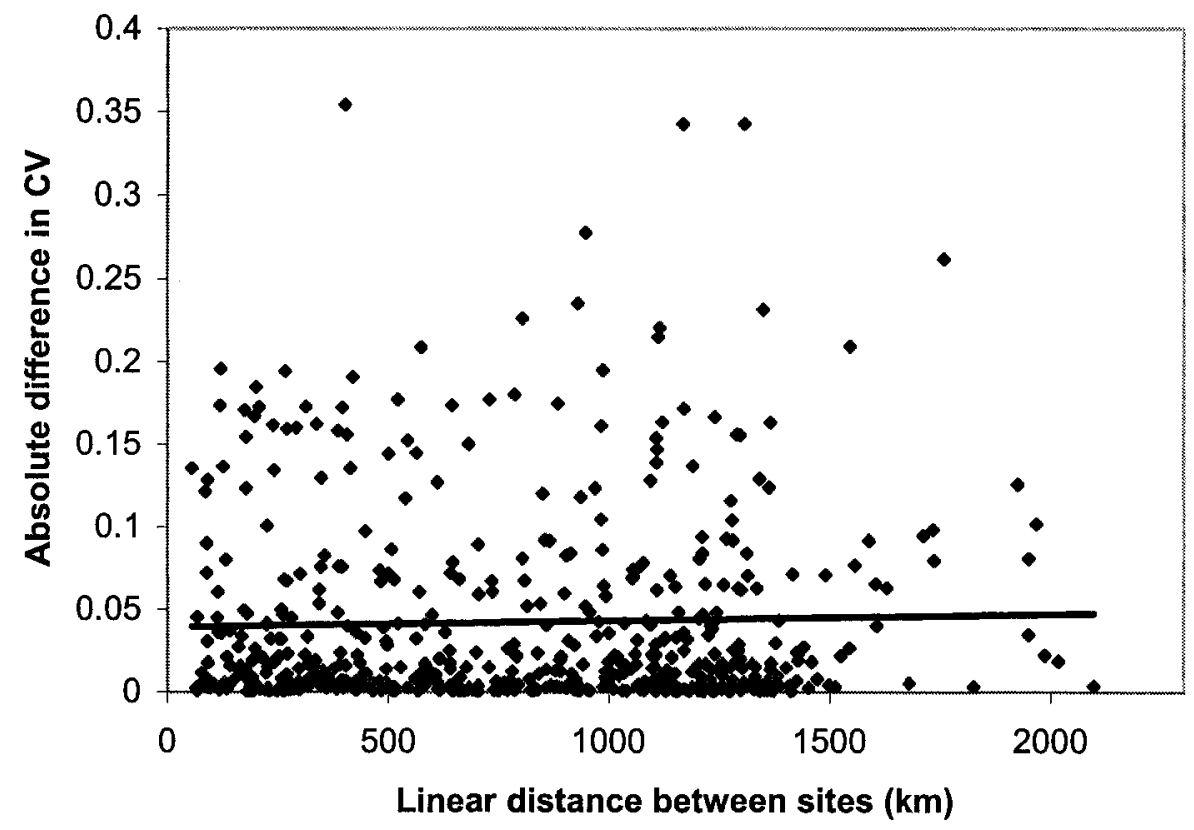

$R^{2}=0.009$

$P=0.03$

B

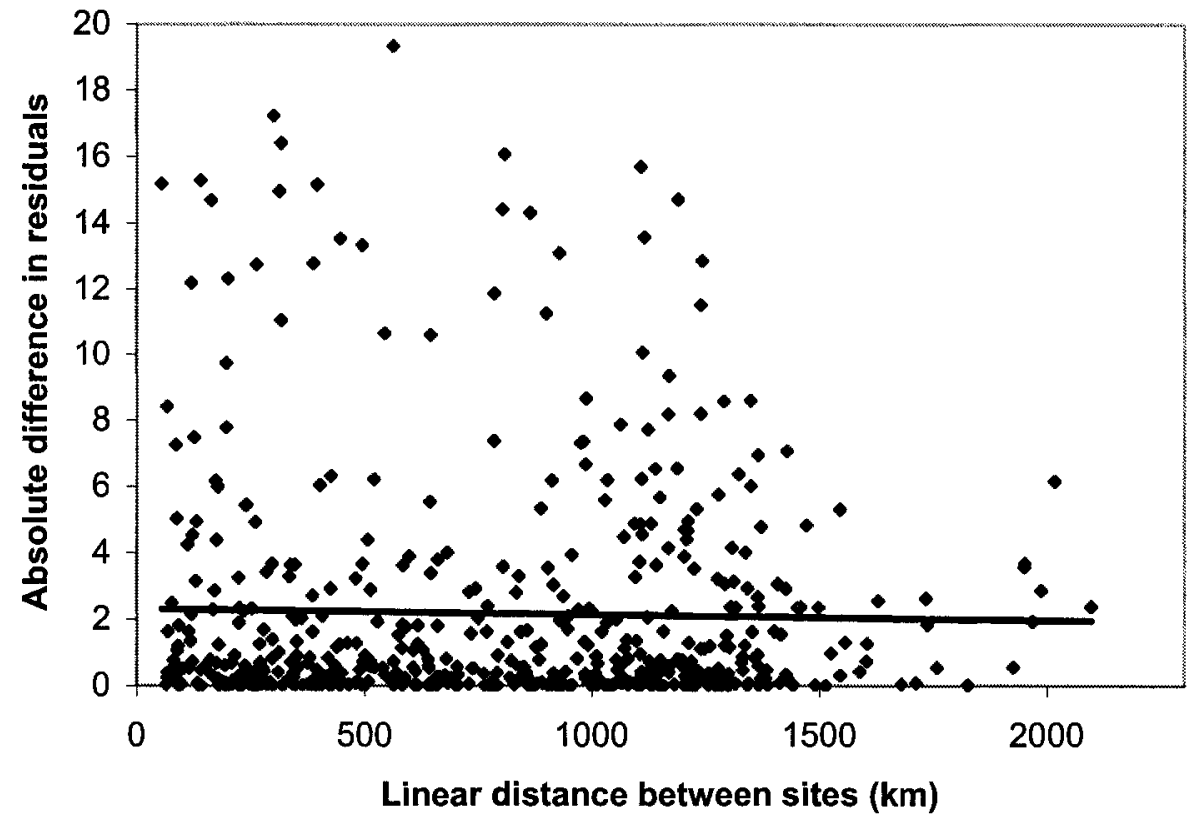

$R^{2}=0.001$

$P=0.40$

Fig 10. Differences in site-specific levels of environmental variation as explained by distance between sites of $T$. canadensis using coefficients of variation (A) and Residuals (B). 
A

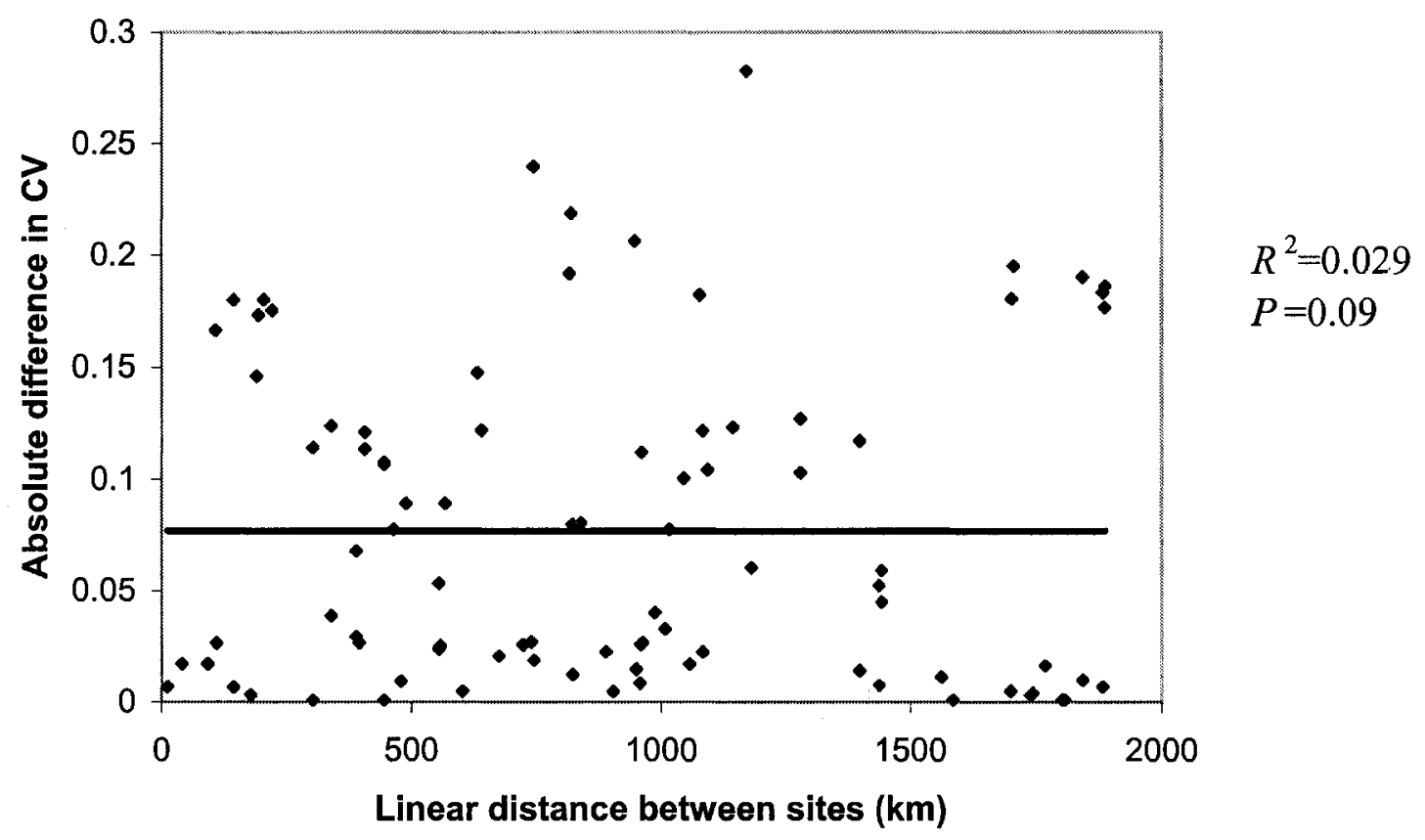

B

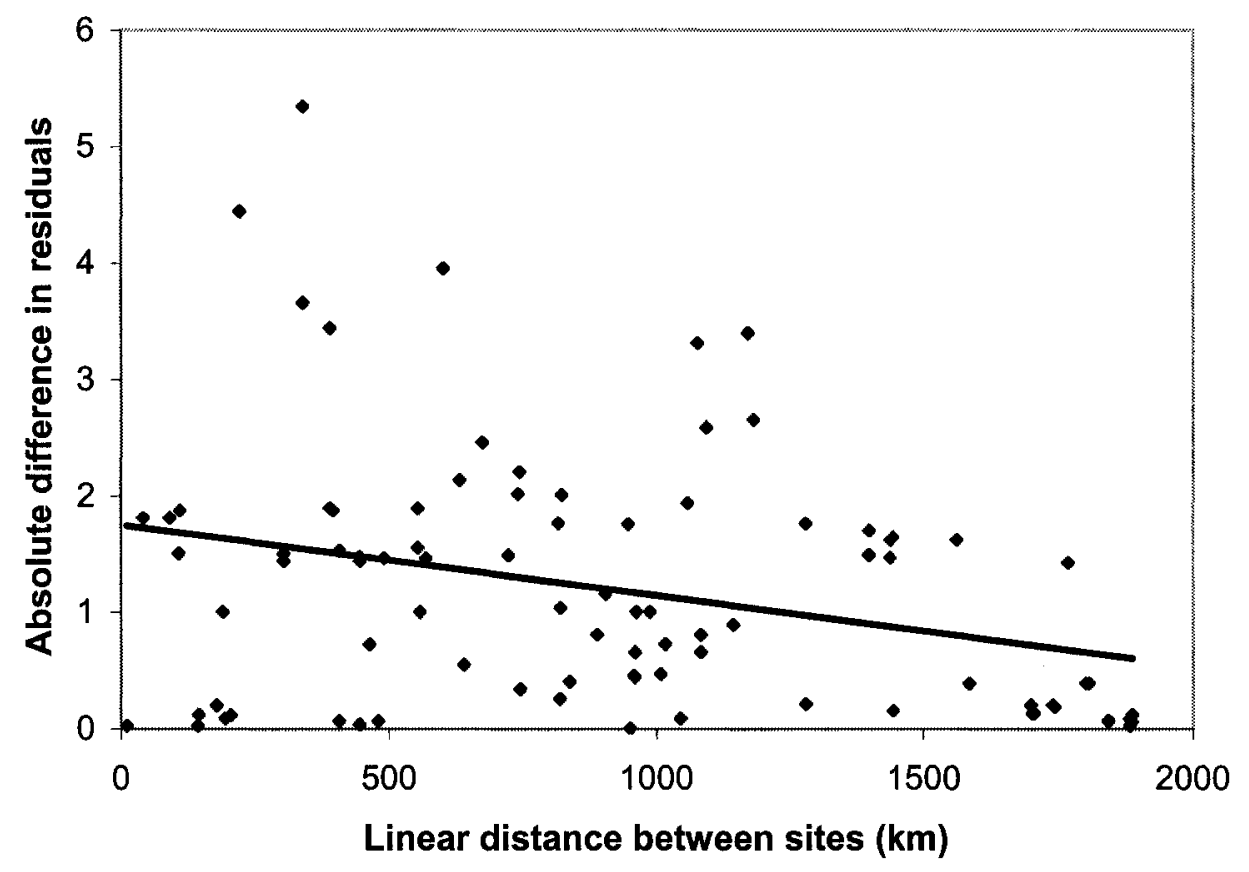

$R^{2}=0.006$

$P=0.46$

Fig 11. Differences in site-specific levels of environmental variation as explained by distance between sites of $P$. strobus using coefficients of variation (A) and Residuals (B). 


\subsection{Discussion}

The evolution of bet-hedging traits depends on the extent of environmental variation. Therefore, to effectively test bet-hedging theory, a framework is needed for quantifying the environmental variation under which the organism has evolved. Traditionally, this has involved the interpretation of meteorological data to provide a framework of the environmental variation selecting for bet-hedging characteristics (Philippi, 1993a; Philippi, 1993b; Nilsson et al., 1996; Clauss and Venable, 2000; Simons and Johnston, 2003). This approach often suffers from the use of a single climate variable, interpreted to be the most limiting factor (for example rainfall in deserts Philippi, 1993a), to provide a history of fluctuating environmental variation. Using more climate variables in a single study results in a great increase in complexity; a record of those variables must first be gathered, and then their joint effect determined. Extremely complex relationships exist between biotic organisms and their environments (Fig. 1 \& 2), rendering it virtually impossible to accurately model the complex interactions of measurable environmental variables and the resulting biotic response.

A biocentric measure of cumulative environmental variation is needed to provide a framework under which selection acts on natural history characters. Dendrochronology has the potential to provide this framework as it can be used to obtain long-term biocentric measures of environmental variation.

In this study, coefficients of variation in mean ring width $(M R W)$ and residuals from a $M R W /$ variance in ring-width plot were used to correct for differences in $M R W$ across sites. This was done to correct for the strong relationship between variance and $M R W$ (Fig. $7 \& 8$ ), as the purpose of this study was to detect how variable the environments are at each site, irrespective of how long an average season might be (as 
evidenced by width of an average tree-ring). Because sites with larger ring-widths will naturally have a larger potential variance, this must be corrected for to achieve a measure of environmental predictability (variance in annual ring-growth) which would allow for site comparisons.

\subsubsection{Detecting differences in site-specific environmental variation}

Results from this study show that the techniques of dendrochronology can be applied to detect differences in levels of environmental variation between sites using both Tsuga canadensis and Pinus strobus (Tables $3-6$ and Fig. $5 \&$ 6). These differences were detectable and significant using both $C V$ and residuals from a $M R W /$ variance plot (Table $3 \& 4$ ) to correct for differences in $M R W$ across sites.

While coefficients of variation have traditionally been used to correct for differences in mean (Sokal and Brauman, 1980), because a strong relationship was detected between $C V$ and mean (Fig. 7), the use of residuals may be a preferable measure for comparison of SSEV as they retain no relationship with MRW in either T. canadensis (Fig. 7), or P. Strobus (Fig. 8).

\subsubsection{Detecting trends in environmental variation}

Because season length in Eastern North America tends to decrease with increasing latitude and with increasing altitude, there was an expectation that differences in site-specific environmental variation (SSEV) should be detectable along gradients in these measures. Because I expected decreased season length to correspond with increased variance (as a short-term fluctuation in the environment would consist of a larger proportion of the available season), I predicted that higher elevations and higher latitudes should experience higher levels of SSEV. Because longitude in Eastern North America is loosely associated with proximity to the Atlantic Ocean and its moderating 
influence on climate, detection of a relationship between increasing longitude and increased $S S E V$ was also expected.

Tests of these predictions did not yield the expected results. In comparisons of individual site-location variables with measures of $S S E V$, coefficients of variation explained more of the variance in SSEV than did the residual-based measure, however, these comparisons were not as simple as they seem, because higher altitude sites tended to be found at lower latitudes (most notably in T. canadensis -Tables $1 \& 2$, Fig. 9), complicating the analysis by linking the variables under study.

Multiple linear regressions were performed in an attempt to describe the relationships between the variables and the different measures of SSEV. These tests again showed that the majority of variance in $S S E V$ is not explained by site-location variables alone (Tables $7 \& 8$ ). In fact, the only multiple linear regression model that described more than $6 \%$ of the variance in $S S E V$ values was that using the $C V$-measure for $P$. strobus $\left(R^{2}=0.306-\right.$ Table 8$)$. T. canadensis showed the strongest parameter estimates, with the residual-measure of $S S E V$ in this case showing:

for latitude: $0.719, \mathrm{p}<0.01$

for longitude: $-0.394, \mathrm{p}<0.01$ (Table 7).

The inability of site-location variables to explain a large portion of the differences in SSEV detected through dendrochronological analyses would seem to indicate the predominance of in-site variables over the large scale variables associated with site location.

A second study was performed to determine the relationship between siteproximity and SSEV. For this study, pair-wise distances between sites were used to compare absolute differences in the $C V$-based and residual-based measures of SSEV. Of 
the 4 combinations of species and SSEV measure (Fig. $10 \& 11$ ), only the combination of the $C V$-based measure and $T$. canadensis provided significant results (though with an extremely low $R^{2}$ value). The use of pair-wise comparisons greatly inflates the degrees of freedom associated with this study and could potentially be better addressed through use of a Mantel's test. However, based on the low $R^{2}$ values associated with these comparisons, there is no biologically meaningful relationship between site-location and levels of $S S E V$. Even sites that are found in relatively close proximity to one another do not share common values of SSEV.

These results strengthen the argument in favour of dendrochronology as a method of providing a cumulative biotic measure of $S S E V$ for use in life-history analyses. Because variation in annual ring-width measurements can be distinguished independent of site proximity, or geographic location, dendrochronology can be used to detect differences in SSEV between sites in close proximity to one another, or widely separated along geographic gradients.

A large volume of work has been published on dormancy fractions in the seeds of monocarpic plants, as models for investigating the evolution of life history traits (for examples - Venable and Lawlor, 1980; Bulmer, 1984; Brown and Venable, 1986; Ellner 1986; Ellner, 1987; Venable and Brown, 1988; Philipi, 1993a; Philipi, 1993b; Pake and Venable, 1996; Clauss and Venable, 2000; Simons and Johnston, 2000; Simons and Johnston, 2003). Assuming that variation in the width of annual tree-rings is correlated with fitness variation in monocarpic plants, dendrochronology may be aptly suited to provide a cumulative, biocentric measure of the site-specific environmental variation that characterizes the selection for life-history characters in these plants. This cumulative biocentric measure would represent the combined effect of multiple climate variables, a 
more complete measure than that which has been used in bet-hedging studies based on a single quantitative measure of environmental variation (Chapter I). It is not yet possible to equate environmental variation as estimated by tree-ring analysis to variance in herbaceous fitness. This assumption is still being tested (Simons' Lab, Carleton University), and if confirmed, would allow levels of environmental variation detected through tree-ring analyses to be directly linked to variation within herbaceous plants.

Potential obstacles to the detection of such a close correlation include differential response of trees and herbaceous plants to sources of variation in tree ring-width. Trees have energy reserves in the form of storage tissues which could reduce the variation in growth caused by short short-term fluctuations in climate. As herbaceous plants do not have the same energy reserves, the level of environmental variation they experience may be higher than that recorded in tree-rings. The external influence of host-specific forms of herbivory on tree-ring growth are detectable using dendrochronology (Fritts \& Swetnam, 1989), and could result in increased levels of SSEV associated with a tree ringwidth based measure of environmental variation. The simultaneous use of different tree species to measure levels of SSEV would avoid the potential problems associated with host-specific insect outbreaks.

Even if tree-ring growth response to environmental variation is not found to correlate with that of monocarpic plants, the detectable differences in SSEV still provide a long-term, biocentric measure of the level of environmental predictability associated with a given site. This measure is in itself extremely valuable, as it may allow for the development of testable predictions based on the long-term levels of environmental unpredictability that characterize a given study site. 


\subsubsection{Future considerations}

Although I have shown that it is possible to detect differences in SSEV using the techniques of dendrochronology, there remain more avenues of detailed analyses to be conducted. As an example of how dendrochronological analyses might aid research on bet-hedging in annual plants, tree-ring growth can provide an insight to frequency of poor growing seasons (Fig. 12). This sample figure demonstrates how tree-ring analysis could clearly indicate the frequency of poor growing years, as well as the relative severity of that year. Comparing such site histories could allow predictions to be made on dormancy fractions based on actual histories of SSEV, and then allow these predictions to be tested through field and greenhouse studies.

The spectral nature and accumulation of environmental variation over time are topics that have been addressed extensively in the literature (e.g.: Pimm, 1984; Pimm and Redfearn, 1988; Cyr, 1997; Bengtsson et al., 1997; Pablo and Halley, 2002).

Dendrochronology could potentially be used in this area of research. Sites which have similar measures of $S S E V$ may be found to have accumulated that total variance measure in different ways. As an example (Fig. 13) one site may be relatively stable over time, with a few widely spaced large disturbance events. A second site may experience far less environmental stability from year to year, but because the magnitude of the variations is smaller than those experienced by the first site, this second site will, in the end, have the same characteristic SSEV as measured over the time period of interest. Dendrochronology should allow for comparisons of the spectral nature of environmental variation on a site-by-site basis, providing a long-term, stationary, biocentric measure of environmental variation. 


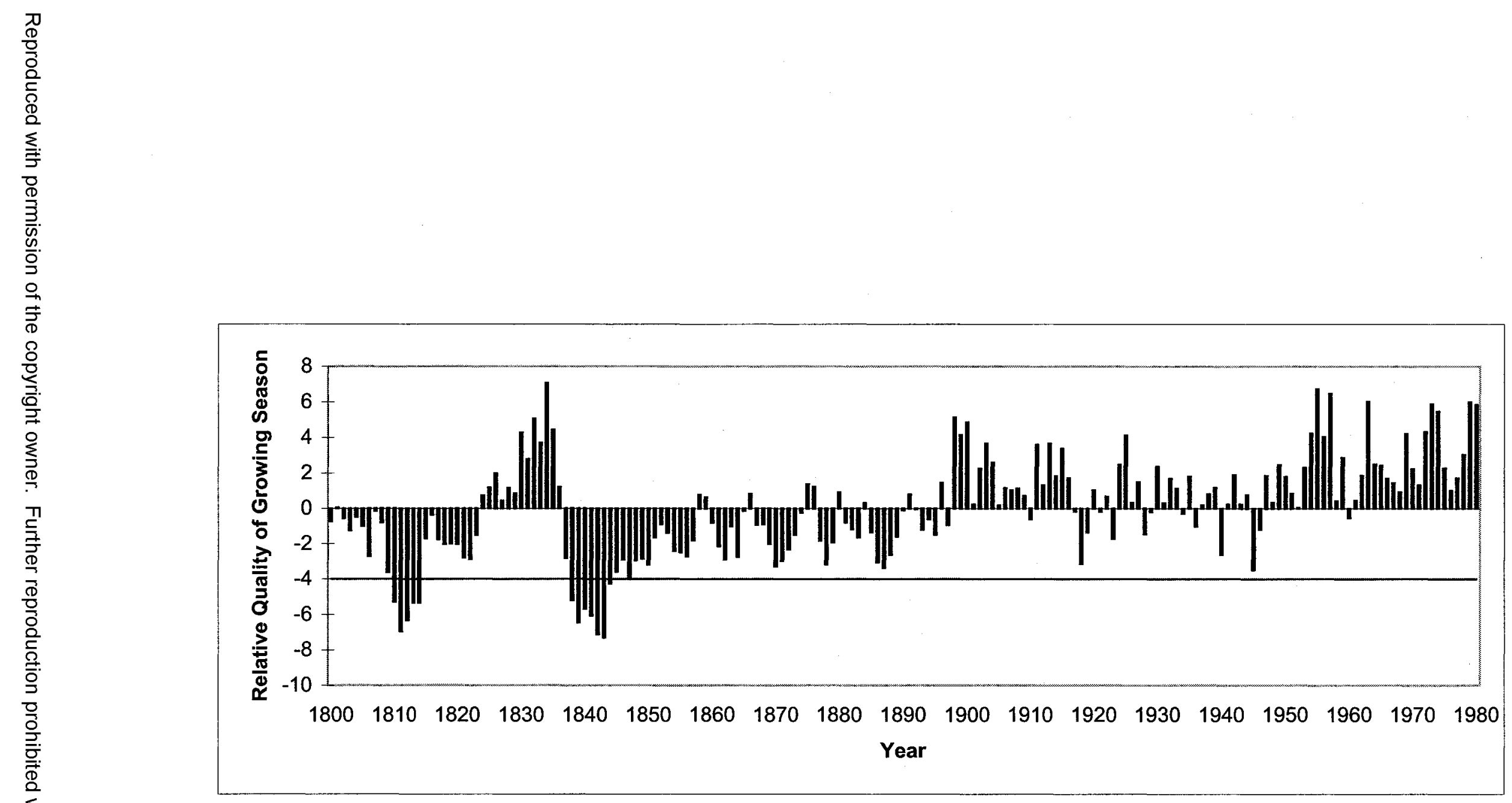

Fig 12. Demonstration of how tree-ring analysis could provide a frame of reference for studying fitness in annual plants. Values are calculated by subtracting site mean ring-growth from annual ring-width values. In this figure, the relative quality of a growing season is clearly evident, with more strongly negative years possibly correlating with poor or zero fitness in germinating annual plants. Here value of -4 (based on $50 \%$ of mean ring-growth for the site) is used as an indicator of the zero fitness point for an annual plant, this value was selected arbitrarily and may be higher or lower in practice. (Ring measurements drawn from Bowater-Mersey site). 


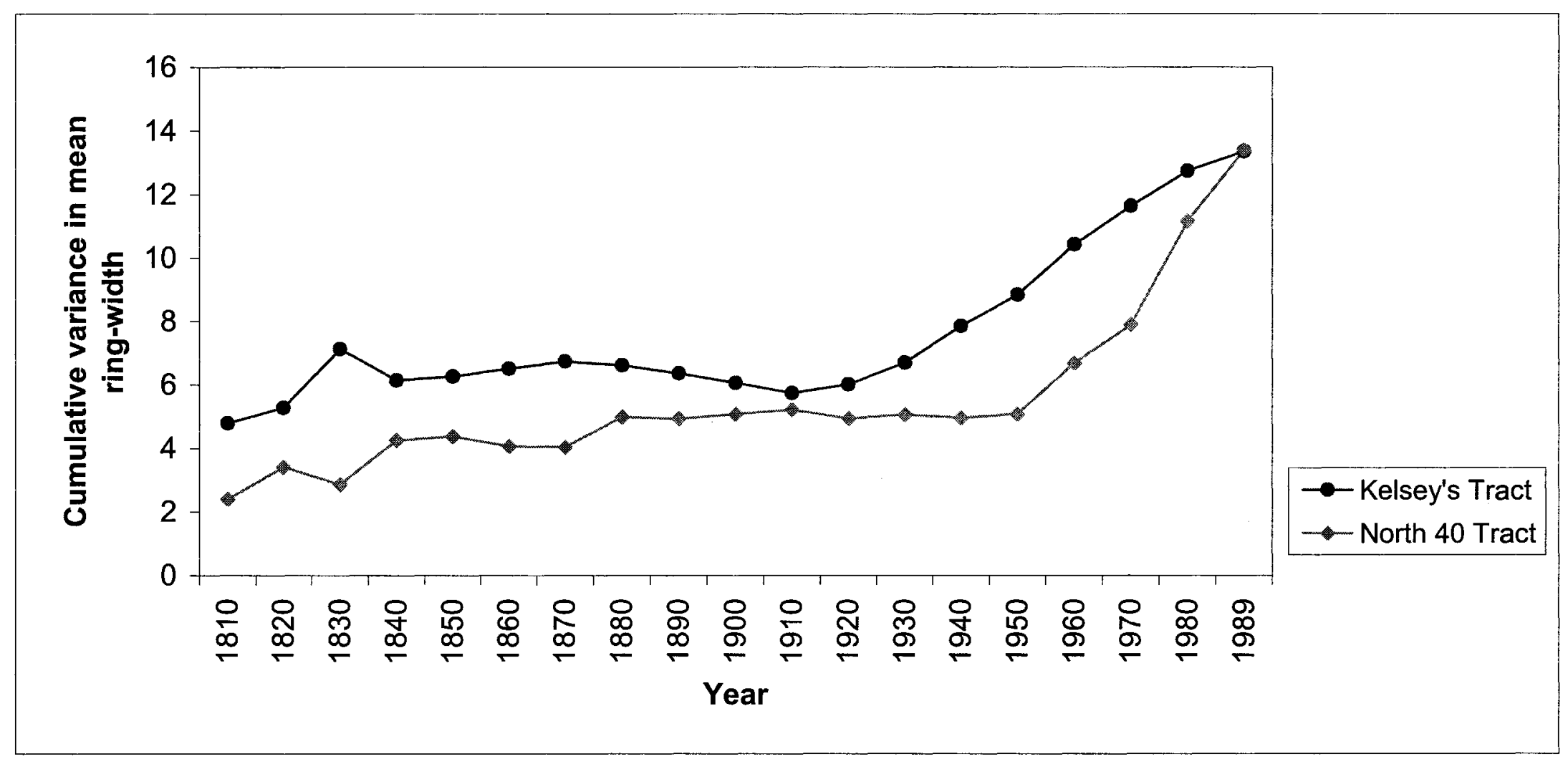

Fig 13. Sample figure showing accumulation of variance in tree ring-width at two different sites. Sites chosen based on their having the same cumulative measure of variance as measured from 1810 to 1989. 
The results of this study, while significant, may have been stronger had the sites used for these analyses been chosen based on their expected levels of environmental predictability. As it stands, the sites used in this study were collected by many researchers with their own studies in mind. This collection represents a truly random sampling of sites, and the ability of these studies to detect significant differences in levels of site-specific variance across sites only serves to reinforce its suitability for this form of research.

\subsection{Conclusion}

The techniques of dendrochronology are capable of detecting significant differences in variance of annual tree ring-widths between sites. These differences are independent of site-location and site-proximity. Based on the results of this study, dendrochronology is a viable method of measuring site-specific environmental variation for use in life-history analyses. 


\subsection{References}

Aalberberg, G. and T. Litt. 1998. Multiproxy climate reconstructions for the Eemian and Early Weichselian. Journal of Quaternary Science 13: 367-390.

Becker, B., B. Kromer and P. Trimborn, 1991. A stable-isotope tree-ring timescale of the late Glacial/Holocene boundary. Nature 353: 647-649.

Bengtsson, J., S.R. Baillie and J. Lawton. 1997. Community variability increases with time. Oikos 78: 249-256.

Briffa, K. R., T.S. Barthoolin, D. Eckstein, P.D. Jones, W. Karlen, F.H. Schweingruber, and J. Zetterburg. 1990. A 1400-year tree-ring record of summer temperatures in Fennoscandia. Nature 346: 434-439.

Brown, J.S. and D.L. Venable. 1986. Evolutionary ecology of seed bank annuals in temporally varying environments. American Naturalist 127: 31-47.

Bryson, R.A. and P.R. Julian. 1962. Proceedings of the conference on the climate of the Eleventh and Sixteenth centuries, Aspen, Colorado. NCAR technical notes 63-1. National Centre for Atmospheric Resaech, USA. 102pp.

Bulmer, M.G. 1984. Delayed germination of seeds: Cohen's model revisited. Theoretical Population Biology 26: 367-377.

Castellano, E., S. Becagli, J. Jouzel, A. Migliori, M. Severi, J.P. Steffenson, R. Traversi and R. Udisti. 2004. Volcanic eruption frequency over the last $45 \mathrm{ky}$ as recorded in Epica-Dome $\mathrm{C}$ ice core (East Antarctica) an its relationship with climate changes. Global and planetary change 42: 195-205.

Clauss, M.J. and D.L. Venable. 2000. Seed germination in desert annuals: an empirical test of adaptive bet hedging. American Naturalist 155: 168-186. 
Cohen, D. 1966. Optimizing reproduction in a randomly varying environment.

Journal of Theoret. Biol. 12: 119-129.

Contributors of the International Tree-Ring Data Bank, IGBP PAGES/World Data Center for Paleoclimatology, NOAA/NGDC Paleoclimatology Program, Boulder, Colorado, USA.

Cook, E.R., and L.A. Kairiukstis. 1990. Methods of Dendrochronology. Kluwer Academic Publishers, USA.

Cyr, H. 1997. Does inter-annual variability in population density increase with time? Oikos 79: 549-558.

Cyr, H. and I. Cyr. 2003. Temporal scaling of temperature variability from land to oceans. Evolutionary Ecology Research 5: 1183-1197.

Danforth, B.N. 1999. Emergence dynamics and bet hedging in a desert bee, Perdita portalis. Proceedings of the Royal Society of London 266: 1985-1994.

Dempster, E. R. 1955. Maintenance of genetic heterogeneity. Cold Spring Harbor Symposium on Quantitative Biology 20: 25-32.

Elias, S.A. and J.V. Matthews. 2002. Arctic North American seasonal temperatures from the latest Miocene to the Early Pleistocene, based on mutual climatic range analysis of fossil beetle assemblages. Canadian Journal of Earth Science 39: 911-920.

Ellner, S. 1985. ESS germination strategies in randomly varying environments. II Reciprocal yield-law models. Theoretical Population Biology 28: 80-115.

Ellner, S. 1986. Germination dimorphisms and parent-offspring conflit in seed germination. Journal of Theoretical Biology 123: 173-185. 
Ellner, S. 1987. Competition and dormancy: a reanalysis and review. American Naturalist 120: 798-803.

Felis, T. and J. Patzold. 2003. Climate records from Corals. Marine Science Frontiers for Europe 11-27 - edited by G. Wefer, F. Lamy, and F. Mantoura, SpringerVerlag, Berlin.

Fritts, H. C. 1976. Tree-rings and climate. Academic Press, London: 1-567.

Fritts, H.C. and T.W. Swetnam. 1989. Dendroecology: a tool for evaluating variations in past and present environments. Advances in Ecological Research 19: 111-188.

Gillespie, J.H. 1974. Natural Selection for within-generation variance in offspring number. Genetics 76: 601-606.

Goodfriend, G.A. 1992. The use of land snail shells in paleoenvironmental reconstruction. Quaternary science review 11: 665-685.

Goodfriend, G.A. and G. L. Ellis. 2002. Stable carbon and oxygen isotopic variations in modern Rabdotus land snail shells in the southern Great Plains, USA, and their relation to environment. Geochimica et Cosmoshemica Acta 66: 1987-2002.

Goudie, A. 1992. Environmental change: contemporary problems in geography. Clarendon press, Oxford.

Gribbon, J. 1978. Climatic change. Cambridge University Press, London.

Griffiths, A.J.F, J.H. Miller, D.T. Suzuki, R.C Lewontin and W.M. Gelbart. 1996. Genetic Analysis (6 $6^{\text {th }}$ Ed.). W.H. Freeman and Com., New York. 779-816.

Grissino-Mayer, H. D. 2005. The ultimate tree-ring web pages. http://web.utk.edu/ grissino.

Halley, J.M. 1999. Extinction risk and the 1/f family of noise models. Theoretical Population Biology 56: 215-230. 
Hanski, I. and I.P. Woiwood. 1993. Mean-related stochasticity and population variability. Oikos 67: 29-39.

Hopper, K.R. 1999. Risk-spreading and bet-hedging in insect population biology. Annual Review of Entomology 44: 535-560.

Horowitz, A. 1989. Continuous pollen diagram for the last 3.5 m.y. from Israel: Vegetation, climate and correlation with the oxygen isotopic record. Paleogeography, Paleoclimatology and Paleoecology 72: 63-78.

Inchausti, P. and J. Halley. 2002. The long-term variability and spectral colour of animal populations. Evolutionary Ecology Research 4: 1033-1048.

Jacoby, G. C., P.R. Sheppard and K.E. Sieh. 1988. Irregular recurrence of large earthquakes along the San Andreas Fault: Evidence from trees. Science 241: 196199.

Jassby, A.D. and T.M. Powell. 1990. Detecting changes in ecological time series. Ecology 71: 2044-2052.

Kendall, B.E. and G.A. Fox. 2002. Variation among individuals and reduced demographic stochasticity. Conservation Biology 16: 109-116.

Kienast, F., and R.J. Luxmoore. 1988. Tree-ring analysis and conifer growth responses to increased atmospheric $\mathrm{CO}_{2}$ levels. Oecologia 76: 487-495.

Laakso, J., V. Kaitala. and E. Ranta. 2001. How does environmental variation translate into biological processes? Oikos 92: 119-122.

Laakso, J.,V. Kaitala, and E. Ranta. 2003. Nonlinear biological responses to disturbance: consequences on population dynamics. Ecological Modelling 162: 247-258. 
Laakso, J., K. Löytynoja, and V. Kaitala. 2003. Environmental noise and population dynamics of the ciliated protozoa Tetrahymena thermophila in aquatic microcosms. Oikos 102: 663-671.

Lande, R. 1993. Risks of population extinction from demographic and environmental stochasticity and random catastrophes. American Naturalist 142: 911-927.

Le Roy Ladurie, E. 1971. Times of feast, times of Famine: a history of climate since yr 1000. Doubleday, New York.

Lewellen, R.H. and S.H. Vessey. 1998. The effect of density dependence and weather on population size of a polyvoltine species. Ecological Monographs 68: 571-594.

Martinelli, N. 2004. Climate from dendrochronology: latest developments and results. Global and Planetary Change 40: 129-139.

McArthur, R.H. and E.O. Wilson. 1967. The Theory of Island Biogeography. Princeton University Press, Princeton.

Meko, D.M. and C.H. Baisan. 2001. Pilot study of latewood-width of conifers as an indicator of variability of summer rainfall in the North American Monsoon Region. The International Journal of Climatology 21: 697-708.

Menu, F, J.P. Roebuck and M. Viala. 2000. Bet-Hedging diapause strategies in stochastic environments. American Naturalist 155(6): 724-734.

National Climate Data Centre for Paleoclimatology (NCDCP). 2005. http://www.ncdc.noaa.gov/paleo/treering.html. Asheville North Carolina, USA.

Nilsson, P., J. Tuomi and M. Astrom. 1996. Bud dormancy as a bet-hedging strategy. The American Naturalist 147: 271-281. 
Pake, C. and D.L. Venable. 1996. Seed banks in desert annuals: implications for persistence and coexistence in variable environments. Ecology 77: 1247-1435.

Patterson, W.P. 1999. Oldest isotopically characterized fish otoliths provide insight to Jurassic continental climate of Europe. Geology 27(3): 199-202.

Periano, A., C. Morri, C.N. Bianchi, J.Aguirre, F. Antonioli, G.Calzetta, L. Carobene, G. Mastronuzzi, P. Orru. 2004. The Meidterranean coral Cladocra caespitose: a proxy for past climate fluctuations? Global and Planetary Change 40: 195-200

Philippi, T. 1993a. Bet-hedging germination in desert annuals: beyond the first year. American Naturalist. 142: 474-487.

Philippi, T. 1993b. Bet-hedging germination of desert annuals: variation among populations and maternal effects of Lepidium lasiocarpum. American Naturalist. 142: 488-507.

Philippi, T. \& J. Seger. 1989. Hedging One's Evolutionary Bets, Revisited. Trends in Ecology and Evoution. 42: 41-44.

Pimm, S.L. 1984. The complexity and stability of ecosystems. Nature 307: 321-326.

Pimm, S.L. and A. Redfearn. 1988. The variability of population densities. Nature 334: 613-614.

Pittock, A.B., L.A. Frakes, D. Jenssen, J.A. Peterson, and J.W. Zillman. 1978. Climatic change and variability - A Southern perspective. University Press, Cambridge.

Raup, D.M. 1991. Extinction: Bad genes or Bad Luck? W.W. Norton Company, inc., New York.

Rees, M., D. Z. Childs, K.E. Rose, and P.J. Grubb. 2003. Evolution of size-dependant flowering in a variable environment: partitioning the effects of fluctuating selection. Proceedings of the Royal Society of London Published Online 
Russell, G.J., J.M. Diamond, S.L. Pimm, and T.M. Reed. 1995. A century of turnover: community dynamics at three timescales. Journal of Animal Ecology 64: 628641.

Scuderi, L. A., 1990. Tree-ring evidence for climatically effective volcanic eruptions. Quaternary Research 34: 67-85.

Seger, J. \& H. J. Brockmann. 1987. What is bet-hedging? Oxford Survey of Evolutionary Biology 4:182-211.

Shaffer, H.B., R.N. Fisher and C. Davidson. 1998. The role of natural history collections in documenting species declines. Trends in Ecology and Evolution 13: 27-30.

Shugart, H.H., N.F. French, E.S. Kasischke, J.J. Slawski, C.W. Dull, R.A. Schuchman and K. Mwangi. 2001. Detection of vegetation change using reconnaissance imagery. Global Change Biology 7: 247-252.

Simons, A.M. 2002. The continuity of microevolution and macroevolution. Journal of Evolutionary Biology 15: 688-701.

Simons, A. M. and M.O. Johnston. 2000. Variation in seed traits of Lobelia inflata: sources and fitness consequences. American Journal of Botany 87 (1): 214-131.

Simons, A.M. and M.O. Johnston. 2003. Suboptimal timing of reproduction in Lobelia inflata may be a conservative bet-hedging strategy. Journal of Evolutionary Biology 16: 233-243.

Simovich, M. A. \& T. A. Hathaway. 1997. Diversified bet-hedging as a reproductive strategy in ephemeral pool anostracans (Branchiopoda). J. Crustacean Biol. 17: $38-44$. 
Sinka, K.J. and T.C. Atkinson. 1999. A mutual climatic range method for reconstructing palaeoclimate from plant remains. Journal of the geological society 156: 381-396.

Slatkin, M. 1974. Hedging one's evolutionary bets. Nature 250: 704-705.

Sokal, R.R. and C.A. Braumann. 1980. Significance tests for coefficients of variation and variability profiles. Systematic Zoology 29: 50-66.

Stefanini, M.C. 2004. Spatio-temporal analysis of a complex landslide in the Northern Apennines (Italy) by means of dendrochronology. Geomorphology 63: 191-202.

Stocker, T.F. 1999. Abrupt climate changes: from the past to the future - a review. International Journal of Earth Sciences 88: 365-374.

Thompson, L.G. 2000. Ice core evidence for climate change in the Tropics: implications for our future. Quaternary Science Reviews 19: 19-35.

Venable, D.L. and J.S. Brown. 1988. The selective interactions for dispersal, dormancy and seed size as adaptations for reducing risk in variable environments. American Naturalist 131: 360-384.

Venable, D.L. and L. Lawlor. 1980. Delayed germination and dispersal in desert annuals: escape in space and time. Oecologia 46: 272-282.

Weatherhead, PJ, G. Blouin-Demers and \& K.A. Prior. 2002. Synchronous variation and long-term trends in two populations of black rat snakes. Conservation Biology 16: 1602-1608.

Yasue, K., R. Funada, K. Fukazawa and J. Ohtani. 1997. Tree-ring width and maximum density of Picea glenhnii as indicators of climatic changes in northern Hokkaido, Japan. Canadian Journal of Forestry Research 27: 1962-1970. 
Zeide, B. 1992. Has Pine Growth Declined in the Southeastern United States?

Conservation Biology 6: 185-195. 